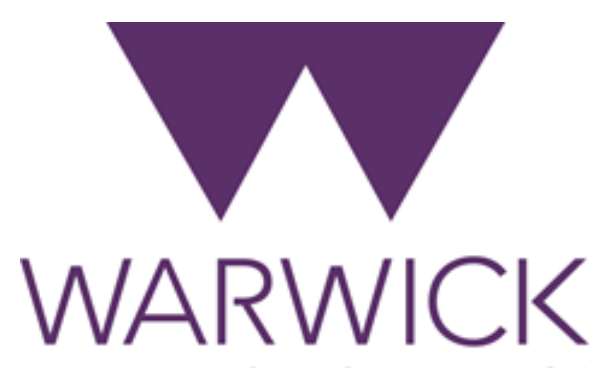

THE UNIVERSITY OF WARWICK

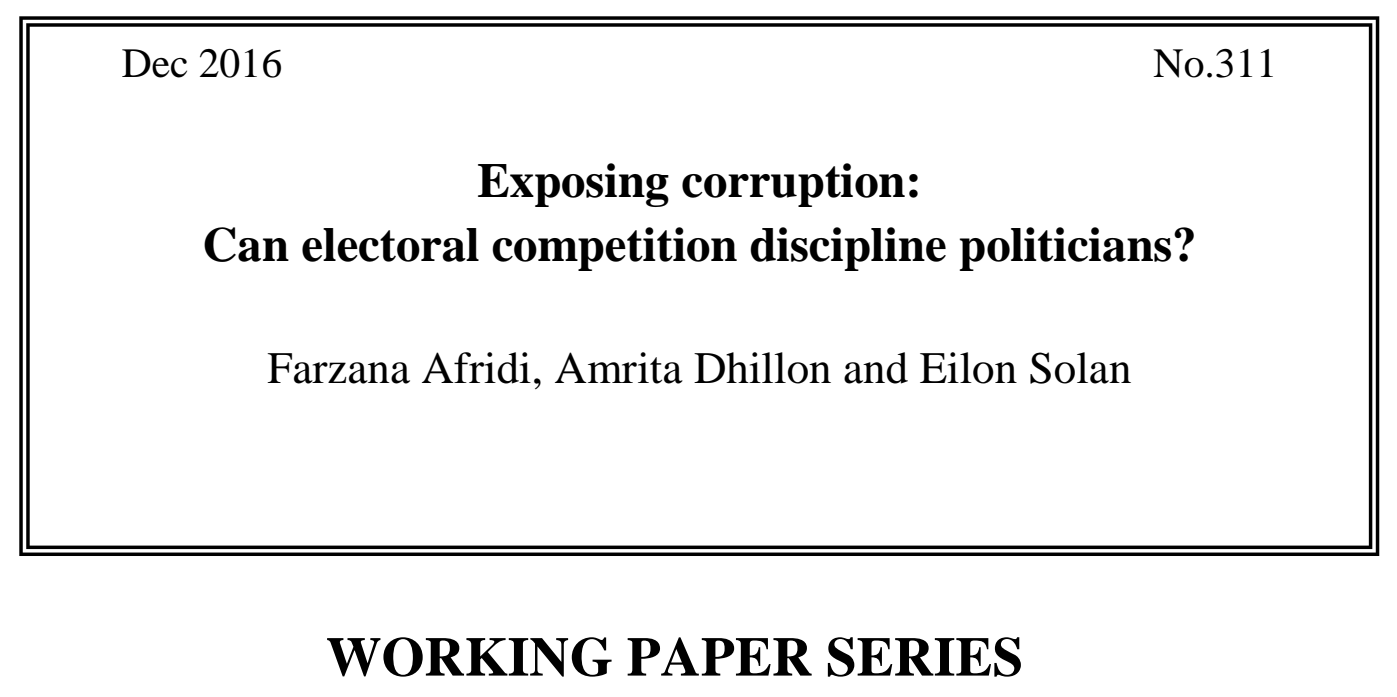

Centre for Competitive Advantage in the Global Economy

Department of Economics 


\title{
Exposing corruption: Can electoral competition discipline politicians?*
}

\author{
Farzana Afridi $^{\dagger} \quad$ Amrita Dhillon $^{\ddagger} \quad$ Eilon Solan $^{\S}$
}

November 26, 2016

\footnotetext{
${ }^{*}$ The authors thank seminar and conference participants at the Indian Statistical Institute, (Delhi), NOPOOR workshops at Delhi and Oxford, Inequality, Poverty and Mobility Workshop, Queen Mary University London, SERI (IGIDR), Indian Institute of Technology, Delhi and Jawaharlal Nehru University. Afridi thanks the Department of Rural Development, Government of Andhra Pradesh, particularly R. Subrahmanyam and Sowmya Kidambi, for giving access to the audit reports. Bhaskar Datta, Mukesh Eswaran, Parikshit Ghosh, Reetika Khera, and Dilip Mookherjee gave valuable inputs on earlier drafts. Swati Sharma provided excellent research assistance. The authors acknowledge financial support of PPRU at the ISI (Delhi), IGC-India Central and NOPOOR (Afridi) and the Israel Science Foundation, grant \#323/13 (Solan).

${ }^{\dagger}$ Economics and Planning Unit, Indian Statistical Institute, Delhi and IZA, Bonn.

${ }^{\ddagger}$ Department of Political Economy, Kings College, London, and CAGE, University of Warwick. Email: amrita.dhillon@kcl.ac.uk.

${ }^{\S}$ School of Mathematical Sciences, Tel Aviv University.
} 


\begin{abstract}
In developing countries with weak institutions, there is implicitly a large reliance on elections to instil norms of accountability and reduce corruption. In this paper we show that electoral discipline may be ineffective in reducing corruption when political competition is too high or too low. We first build a simple game theoretic model to capture the effect of electoral competition on corruption. We show that in equilibrium, corruption has a U-shaped relationship with electoral competition. If the election is safe for the incumbent (low competition) or if it is extremely fragile (high competition) then corruption is higher, and for intermediate levels of competition, corruption is lower. We also predict that when there are different types of corruption, then incumbents increase corruption in the components that voters care less about regardless of competition. We test the model's predictions using data gathered on audit findings of leakages from a large public program in Indian villages belonging to the state of Andhra Pradesh during 2006-10 and on elections to the village council headship in 2006. Our results largely confirm the theoretical results that competition has a non-linear effect on corruption, and that the impact of electoral competition varies by whether theft is from the public or private component of the service delivery. Overall, our results suggest that over-reliance on elections to discipline politicians is misplaced.
\end{abstract}

Keywords: Corruption, Electoral Competition, Audit, Social Acountability. JEL Classification: D72, D82, H75, O43, C72 


\section{Introduction}

It is fairly well established that corruption is costly, both in terms of efficiency and equity in the provision of public services in developing countries (Olken and Pande (2012)). However, evidence suggests that if the political leadership is committed, corrupt institutions can change rapidly (Svensson (2005); Acemoglu and Jackson (2015)). Therefore, the persistence and high incidence of corruption in low income democracies (Svensson (2005); Transparency International (2015)) is puzzling: if electoral competition is fair, and if voters care about honesty, they can punish corrupt incumbents by voting them out of office. Forward looking incumbents will then respond to these incentives by lowering corruption today (e.g. Ferraz and Finan (2011)). But does electoral competition always lead to lower corruption? We investigate this question in a context where legal sanctions for punishing the corrupt are not binding, yet there exists mandated exposure of corruption through audits of public expenditures. We show theoretically that while re-election concerns are important to discipline incumbents, too much electoral competition can have negative consequences both in terms of encouraging higher theft by incumbents and also the diversion of corruption to higher valued corruption that has lower direct impact on citizens. Using data from mandated audits of a large public program in India we find that indeed, there is a non-monotonic, U-shaped relationship between competition and corruption.

We build a theoretical model in which an agent (the incumbent) chooses how much to "steal" from a public program of a given size. This theft is exposed through mandated audits and followed by elections in the next period. The electorate votes on the basis of: (1) own ideology and (2) the observed corruption level of the incumbent relative to the challenger whose ideology is common knowledge but whose corruption level is uncertain. For the incumbent, therefore, the trade-off is between stealing a lot today and lowering the probability of re-election, or stealing less today and having a higher probability of staying in power. $^{1}$ In an infinitely repeated game, we derive the stationary equilibrium level of theft by the incumbent while in office and show that even when voters can perfectly observe corruption, too little or too much competition leads to higher levels of theft. This result is driven by incumbent behavior when the electoral bias is towards her. On the other hand, if the electoral advantage is with the challenger, increases in competition have no impact on corruption. Further, we show that if the incumbent has a choice between theft that affects citizens directly (viz. theft from public funds related to wage payments- we call this type of theft "private") and corruption that is more "public" in nature and does not directly affect

\footnotetext{
${ }^{1}$ Empirical evidence for this kind of an objective function is provided in Niehaus and Sukhtankar (2013).
} 
citizens (viz. through inflated expenditures on materials in construction of public projects), then the responsiveness of corruption to theft in the public goods is much lower relative to theft in the private goods component.

We test our theoretical predictions using data we gathered on one of the largest public programs in India: the National Rural Employment Guarantee Act (NREGA) - a rights based program that aims to guarantee 100 days of annual work to rural households willing to volunteer adult labor to rural public works. As is true with most public programs in developing countries, NREGA has also been besieged with apprehensions about theft and leakage of public funds (Afridi and Iversen (2014)). However, a major concern that plagues most studies on malfeasance in public programs is the lack of objective measures of corruption. A novel feature of the NREGA, distinct from previous workfare programs in India, is mandatory audits of projects implemented under the program. The Act envisages that competent audits will be organized at regular intervals at the village level. The guidelines thus make audits and stakeholder participation therein, the main mechanism to ensure transparency and the accountability of those in charge of program implementation.

We construct panel data on irregularities reported in original audit reports in the state of Andhra Pradesh (AP), a pioneer in institutionalizing audits of NREGA projects, during 2006-10. Data on objective measures of corruption in the NREGA from almost 300 village councils are coupled with information on elections to the position of village council headships in 2006 for a five year term. These village councils are responsible for planning and the subsequent execution of at least 50 percent of all NREGA works.

Using the margin of victory between the top two candidates in the elections as our measure of electoral competition, we show that the data strongly support the theoretical predictions - in the cross-section and particularly when electoral bias is towards the incumbent, corruption responds non-monotonically to higher competition. When the bias is against the incumbent, however, there is low responsiveness of corruption to competition. In line with the theory, we also find that pilferage from the public component of the program is less responsive to competition than the private component.

There exists a large literature on the relationship between electoral competition and various economic outcomes. However, there is a lack of consensus on the relationship between the two. One strand of this literature suggests a positive relationship between electoral competition, economic development, and public service delivery. For instance, Besley et al. (2010) show that for US municipalities, competition has a positive effect on economic outcomes; Ashworth et al. (2014) find that having more parties improves the efficiency of municipal governments in Belgium; Acemoglu and Robinson (2006) show 
theoretically that when elites are either highly entrenched or when the environment is highly competitive, they have lower incentives to block innovation and development. ${ }^{2}$ Within the set of the literature which suggests that electoral competition is welfare enhancing, Svaleryd and Vlachos (2009) and Ferraz and Finan (2011) focus specifically on corruption. While the latter find that leakages are lower in Brazilian municipalities when incumbents have reelection incentives (first term mayors) compared to when they do not (last term mayors), the former show both theoretically and empirically that rents are decreasing both as voter information increases and as competition increases in Swedish municipalities.

Contrary to the above findings, Booth et al. (2011) show that electoral competition may not affect corruption at all, but rather change its nature - with competition, vote buying becomes more attractive than other types of rent seeking. ${ }^{3}$ Other research suggests a negative impact of electoral competition on economic outcomes. Acemoglu and Robinson (2006) and Acemoglu and Robinson (2000) build a model to show that when the incumbent has a choice between investing for the future (which reduces entry costs for competitors) and investing more in getting re-elected, then as political competition becomes more intense, the latter incentive dominates, leading to lower growth. Aidt et al. (2011) point out that in India, the share of criminally accused politicians has been going up as Indian party politics becomes more competitive - when a seat is highly contested and swing, criminal politicians have a comparative advantage in winning elections through intimidation of voters and vote buying. We do not model how corrupt candidates can affect elections by vote buying or intimidation. Our contribution is to show that highly competitive elections can be worse in terms of corruption even without allowing vote buying or adverse selection.

We know of only a few papers in this literature that suggest a non-linear relationship between electoral competition and economic outcomes. Campante et al. (2009) propose a model of incumbent behavior that has two contradictory effects: a horizon effect whereby greater instability leads the incumbent to embezzle more during her shorter stint in office and a demand effect by which the private sector is more willing to bribe stable incumbents. In a cross country study, using perceptions of corruption indices, they show that there is a U-shaped relationship between corruption and instability - regimes that are very stable or

\footnotetext{
${ }^{2}$ In a paper, not directly related to economic outcomes, Banerjee and Pande (2007) build on the idea of citizen candidate models to argue that politician quality is maximized when voter groups are equally sized (high political competition) because it leads parties to compete on a quality dimension. Having a large majority group in an ethnicized population which is voting partly on ethnic lines is a force to reduce politician quality.

${ }^{3}$ Persson et al. (1997) refer to the need to allow some graft by the politician as "power between elections" to prevent excessive looting.
} 
are very unstable generate higher corruption. In a similar vein, Bardhan and Yang (2004) develop a theoretical model that predicts an optimal level of political competition beyond which aggregate welfare can fall due to the reduced incentives to invest in the future.

There are two major innovations in this paper. First, we build a theoretical model, which shows that incumbents' incentives to control corruption may decrease when electoral competition is too low or too high. Although the driving force of our result, like many of the papers cited above, is the incumbent's trade-off between reducing corruption today and thereby increasing her probability of re-election vis-a-vis the gains from stealing more today and a lower probability of survival in the future, the papers that explicitly model corruption and electoral competition show that competition is always good (Besley et al. (2010); Svaleryd and Vlachos (2009)). Second, this paper is the first to provide empirical support for a non-linear relationship between electoral competition and corruption in public good provision. As in Ferraz and Finan (2011), we conduct a within country analysis and use an objective measure of corruption based on independent audits for our empirical results. Unlike the existing literature, which primarily suggests a linear relationship between electoral competition and corruption, we provide empirical support for a more nuanced interaction between the two, distinguishing between types of theft and the varying nature of their responsiveness to competition. In contrast to the existing literature that does not discriminate between types of public programs, we show both theoretically and empirically that theft from government programs that provide pure public goods is less responsive to electoral competition.

Our paper contributes to the emerging view that in democracies with weak institutions, too high a level of electoral competition creates perverse incentives, not only in the selection of worse politicians (Aidt et al. (2011), Mitra and Shajahan (2015)) but also in creating worse incentives while in office. In particular, electoral competition may not always reduce corruption - it may sometimes lead to higher corruption - and it may not have any impact on theft in government programs that deliver pure public goods. Further, our analysis suggests that although mandated exposure of corruption is likely to empower the electorate, it may not always lead to lower theft from public programs if their effects are mediated by the level of electoral competition. Thus the absence of appropriate legal penalties when electoral competition is either too high or too low can render audits ineffective in lowering irregularities in the implementation of public programs. Recent work (Muralidharan et al. (2016)) has shown that interventions such as "smartcards" to identify beneficiaries may lead to reduced leakages in the programme - but indeed, as we show - this is the part of the leakages that is the most responsive to electoral discipline and least in need of an 
intervention of this kind. Interventions aimed at reducing theft in the public component of welfare programs in low income democracies are yet to be seen at scale and would have arguably a larger impact on the total loss to citizens.

Our findings carry some notable implications. First, our results point to the importance of improving voter awareness about the potential leakages in the public component of government of programs. In our context, the magnitude of the irregularities is almost three times larger in this component of the program we study relative to the private component. Second, the analysis, albeit indirectly, highlights the need for enhancing the credibility of an audit process through strict enforcement of legal penalties on the corrupt, rather than relying on elections to provide discipline.

The remainder of the paper is organized as follows: Section (2) describes the model and its predictions. Section (3) presents the institutional background of the NREGA, Section (4) presents the data and methodology while Section (5) presents the results. We conclude in Section (6).

\section{Theoretical Model}

\subsection{The set up}

We present an infinite horizon game in discrete time, where each stage represents one term in office. The main participant in this game (and the only participant to make decisions) is the incumbent at the first stage, who has to determine the amount of money that she steals from the pot of public funds at every stage until she is voted out of office.

Every election, the incumbent faces a challenger, who has a reputation for corruption that is randomly chosen from among the set of potential reputations for corruption. The result of the elections is determined by both the ideology of the two candidates and by their corruption levels.

We now turn to the formal description of the model. There are two types of players in the game: the incumbent and voters, we discuss each one separately.

\section{The Ideology Space:}

There are two parties, L and R, located at opposite sides of the ideology ${ }^{4}$ spectrum, $[-1,1]$. We assume that the ideology of Party $\mathrm{L}$ is -1 and that of Party $\mathrm{R}$ is 1 . There is a

\footnotetext{
${ }^{4}$ There is some debate about whether voters in Indian villages vote on party lines. However, most would agree that there is an element of caste based voting (see, e.g., Munshi and Rosenzweig (2015)) The model can be re-interpreted to deal with caste affiliations instead of parties. The model deals only with two parties but the results extend to situations with multiple parties. In this case the "challenger" can be interpreted
} 
continuum of voters distributed on the ideology space according to a cumulative distribution function $F$ with median $\beta$. The median $\beta$ measures the level of competition: the closer it is to 0 , the fiercer the competition is. When $\beta$ is negative, Party $\mathrm{L}$ has the majority of voters on its side of the ideology spectrum, while when $\beta$ is positive, Party $\mathrm{L}$ is the minority party.

\section{Candidates:}

There is a continuum of potential candidates. Each potential candidate is characterized by two parameters: the party she belongs to ( $\mathrm{L}$ or $\mathrm{R}$ ) and her reputation for corruption. At every period of the game the candidate can either be in or out of office. If the candidate is not in office at stage $t$ (the challenger), then her reputation, denoted by $y_{t}$, which arises from previous public positions she fulfilled, is known. If the candidate is in office at stage $t$ (the incumbent), she determines her corruption level $x_{t}$ at that stage, which becomes public knowledge due to mandated audits of public funds. Potential candidates care about power and rents, so that the payoff of a candidate is

$$
\sum_{t=1}^{\infty} \delta^{t-1} x_{t} \mathbf{P}_{t},
$$

where $\mathbf{P}_{t}$ is the probability that the candidate is in power at stage $t$ and $\delta \in[0,1)$ is the incumbent's discount factor, which is common to all potential candidates. ${ }^{5}$ This objective function captures the trade-off we discussed earlier between present and future corruption - the "golden goose effect" (Niehaus and Sukhtankar (2013)). ${ }^{6}$

\section{Voters:}

Voters care about ideology and about corruption levels. Consider a voter $j$ with ideal point $z_{j} \in[-1,1]$. Then voters' utility from voting for a candidate with corruption level $x$ and ideology $i$ is

$$
U_{j}(x, i):=-x-\left(z_{j}-i\right)^{2}
$$

The utility of the voter is determined by the information the voter has at the moment in which she makes her choice. Hence voter's utility is determined by the observed corruption as the strongest challenger to the incumbent, measured, e.g., by the runner up in the last election. In our data, about $70 \%$ of the incumbents are affiliated with two major political parties. On average, there were 2.9 candidates standing for an election in our sample.

${ }^{5}$ The incumbent can be thought of as putting in costly effort to prevent corruption in her office, with no loss of generality. Our results remain intact when the discount factor is incumbent-specific. In this case the relation between competition and corruption also varies between incumbents.

${ }^{6}$ We abstract from future ego rents from office, which would reduce the incentives to be corrupt now, as it would not change the results qualitatively. 
level of the incumbent and the reputation of the challenger. ${ }^{7}$ Clearly, there are many more dimensions on which voters decide in real elections. Our first key assumption is that, ceteris paribus, the more corrupt a candidate is, the lower the utility of a voter. Our second key assumption is that the most salient "other" dimension is ideology. In a stationary equilibrium these beliefs are rational for the incumbent.

The form of the utility function in Equation (1) is specific, yet it captures the intuition that the voter's utility depends on ideology and is monotonically decreasing in corruption level.

\section{Election Mechanism:}

Elections take place at the end of each period, between the current incumbent, whose corruption level at this period is known, and a challenger, who has a reputation that is uniformly distributed on $[0,1]$. We denote by $x_{t}$ the corruption level of the incumbent at period $t$ and by $y_{t}$ the reputation of the challenger at that stage. Each voter votes according to her utility function. Voter $j$ votes for the incumbent if

$$
-x_{t}-\left(z_{j}+1\right)^{2} \geq-y_{t}-\left(z_{j}-1\right)^{2} .
$$

At the end of period $t$ the incumbent wins the elections if

$$
x_{t}+(\beta+1)^{2}<y_{t}+(\beta-1)^{2} \text {, }
$$

while the challenger wins if ${ }^{8}$

$$
x_{t}+(\beta+1)^{2}>y_{t}+(\beta-1)^{2} \text {. }
$$

Note that $x_{t}+(\beta+1)^{2}<y_{t}+(\beta-1)^{2}$ if and only if $x_{t}+4 \beta<y_{t}$. Since $y_{t}$ is uniformly distributed in $[0,1]$, the probability that the incumbent wins elections is given by:

$$
\theta_{\beta}\left(x_{t}\right):= \begin{cases}1 & x_{t}+4 \beta \leq 0, \\ 1-x_{t}-4 \beta & 0 \leq x_{t}+4 \beta \leq 1, \\ 0 & 1 \leq x_{t}+4 \beta\end{cases}
$$

The function $x_{t} \mapsto \theta_{\beta}\left(x_{t}\right)$ is piecewise linear. Note that it is composed of two parts: if $\beta \leq 0$ then the inequality $1 \leq x_{t}+4 \beta$ cannot hold, hence this function is composed of the

\footnotetext{
${ }^{7}$ Thus, voters are not perfectly rational. This modelling choice is made for simplification. We can show that our results are robust to having rational voters in a more complicated model where the party and candidates are treated as different players.

${ }^{8}$ The case $-x_{t}-\left(z_{j}+1\right)^{2}=-y_{t}-\left(z_{j}-1\right)^{2}$ has probability 0 , hence ignored.
} 
top two inequalities in equation (5), while if $\beta \geq 0$ then the inequality $x_{t}+4 \beta \leq 0$ cannot hold, and therefore the function is composed of the bottom two inequalities in equation (5).

\section{The Timeline of the Game}

- We assume without loss of generality that the incumbent candidate comes from Party L.

- At every stage $t=1,2, \ldots$ until the incumbent loses an election,

- The incumbent candidate, who is from party L, chooses a level of corruption $x_{t}$.

- The corruption level $y_{t}$ of the challenger at stage $t$, who is from Party $\mathrm{R}$, is chosen uniformly from the interval $[0,1]$.

- Voters observe $x_{t}$ and $y_{t}$ and elections take place.

- If the incumbent is re-elected, the game continues to the next stage; otherwise the game terminates.

We denote by $T$ the stage in which the incumbent loses power. ${ }^{9}$ The lifetime discounted payoff to the incumbent is:

$$
\sum_{t=1}^{\infty} \delta^{t-1} x_{t}
$$

\subsection{Equilibrium Analysis}

The solution concept that we study is subgame perfect equilibrium. We note that the only player who makes decisions in our model is the incumbent candidate, hence the game is reduced to a Markov decision problem with two states: the initial state, where the incumbent is in office, and a second, absorbing state, where the incumbent loses power. The decision problem is stationary, hence by Blackwell (1962) (or Puterman (2014) more recently) the incumbent has a stationary optimal policy. That is, there is a fixed optimal amount per period that the incumbent steals until she is voted out of office and the game terminates.

For every $x \in[0,1]$ denote by $\sigma_{x}$ the stationary strategy in which the incumbent steals $x$ at every period until she loses office. Since the probability that the incumbent who steals $x$ wins elections is $\theta_{\beta}(x)$, the probability that under $\sigma_{x}$ the incumbent is in office at stage

\footnotetext{
${ }^{9} T$ is a stopping time, which may be infinity.
} 
$t$ is $\left(\theta_{\beta}(x)\right)^{t-1}$. It follows that the total expected discounted payoff of the incumbent when she uses the stationary strategy $\sigma_{x}$ is

$$
v_{\beta}(x):=\sum_{t=1}^{\infty} \delta^{t-1} x\left(\theta_{\beta}(x)\right)^{t-1}=\frac{x}{1-\delta \theta_{\beta}(x)}
$$

We look for the corruption level $x_{\beta}^{*} \in[0,1]$ that maximizes the total expected discounted payoff $v_{\beta}(x)$. First, assume that $\beta<0$, that is, the electoral advantage is with the incumbent. It is quite intuitive that when the margin of victory for the incumbent is very high, she can steal a large amount without reducing the probability of winning. It turns out that when the margin of victory is very low, the immediate gain from increasing corruption outweighs the loss of future profits due to a lower probability of winning, hence the incumbent will steal the whole pot. In the intermediate range, however, as competition increases, corruption falls. Consider now the case $\beta>0$, so the electoral advantage is with the challenger. When $\beta$ approaches 0 the incumbent steals the whole pot, and therefore a fortiori when $\beta$ is nonnegative there is no incentive to reduce corruption. Claim (1) below summarizes the analysis.

Claim 1 The optimal level of corruption for the incumbent is given by (see Figure 1):

- If $\beta \leq-\frac{1}{4}$, then $x_{\beta}^{*}=1$.

- If $-\frac{1}{4} \leq \beta \leq-\frac{1-\delta}{4 \delta}$, then $x_{\beta}^{*}=-4 \beta$.

- If $-\frac{1-\delta}{4 \delta} \leq \beta$, then $x_{\beta}^{*}=1$.

The proof of this result is in the Appendix. Figure 1 shows how competition and corruption are related: when the electoral advantage with the incumbent is very high $(\beta \leq$ $-\frac{1}{4}$ ) corruption is the maximum at 1 . As $\beta$ increases, the electoral advantage decreases and corruption decreases until it hits the threshold $\beta=-\frac{1-\delta}{4 \delta}$ when competition is very stiff (and is close to 0 if the incumbent is patient). At this point, corruption jumps discontinuously up to the maximum again. Finally when $\beta \geq 0$, the electoral advantage is with the challenger, and the incumbent has no incentive to reduce corruption. The discontinuity is an artefact of the modelling choice where we have a piecewise linear probability of winning function. ${ }^{10}$ The main take away from the figure is the U-shaped relationship between competition and corruption on the left side of Figure 1 (electoral advantage with the incumbent), and the complete unresponsiveness of corruption to competition in the right hand side of Figure 1 (electoral advantage with the challenger).

\footnotetext{
${ }^{10}$ This follows from our assumption of a uniform distribution on the challenger's reputation.
} 
Figure 1: Optimal corruption for different levels of electoral competition

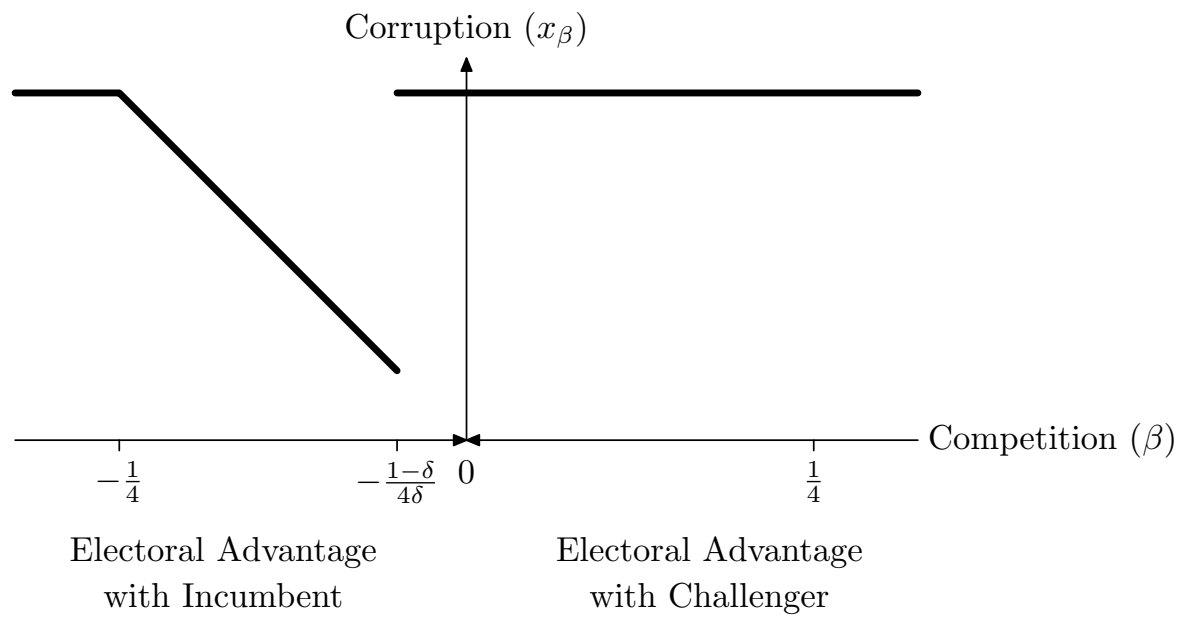

\subsection{The nature of corruption}

The "pot of money" available to incumbents may be allocated to different types of public programs. Some of these provide private benefits to individual citizens directly (e.g., employment, food security, school meals, etc.), while others provide more indirect benefits (e.g., investments in infrastructure such as road construction). In this section, we divide the total pot of money that can be stolen by the incumbent into a "private" component and a "public" component, each of which has a separate budget. ${ }^{11}$

As before, total corruption is denoted by $x_{t}$. Denote by $x_{t}^{\mathrm{pub}} \in\left[0, \frac{1}{2}\right]$ and $x_{t}^{\mathrm{pvt}} \in\left[0, \frac{1}{2}\right]$ the public and private amounts ${ }^{12}$ that the incumbent steals at stage $t$, so that $x_{t}=x_{t}^{\mathrm{pub}}+x_{t}^{\mathrm{pvt}}$.

Assume that voters view corruption in the two types of components differently: they care more about theft from public funds- which provide them pure private benefits- than those that provide pure public benefits. The utility that voter $j$ assigns to an incumbent with ideology $i$ and reputation $\left(x_{t}^{\mathrm{pub}}, x_{t}^{\mathrm{pvt}}\right)$ is

$$
U_{j}\left(x_{t}^{\mathrm{pub}}, x_{t}^{\mathrm{pvt}}, i\right):=-\alpha^{\mathrm{pub}} x_{t}^{\mathrm{pub}}-\alpha^{\mathrm{pvt}} x_{t}^{\mathrm{pvt}}-\left(z_{j}-i\right)^{2},
$$

where $\alpha^{\text {pub }} \geq 0$ and $\alpha^{\text {pvt }} \geq 0$ are coefficients that represent the weights that voters attach

\footnotetext{
${ }^{11}$ Examples in NREGA for the private component include payment of lower than mandated wages to program beneficiaries and payment of bribes to obtain one's due wages from public program participation. The public component includes corruption which does not personally affect citizens. For instance, inflating the cost of materials used in the projects constructed under the program. We will provide more details on this classification in the data section.

${ }^{12}$ The bounds on each part are taken to be symmetric but results do not change even if we assume asymmetric bounds for the two components. The NREGA mandates that at least $60 \%$ of program expenditures be on wage payments and only $40 \%$ on materials used in project construction.
} 
to each type of corruption, and $z_{j}$ is voter's $j$ ideal point in the ideology space. The utility that the voter assigns to a challenger with ideology $i$ and reputation $y_{t}$ is

$$
U_{j}\left(y_{t}, i\right):=-y_{t}-\left(z_{j}-i\right)^{2}
$$

The model we presented in Section (2.1) is equivalent to the present model with $\alpha^{\mathrm{pub}}=$ $\alpha^{\mathrm{pvt}}=1$.

As mentioned above, we assume that voters care more about the private component, hence $\alpha^{\mathrm{pvt}}>\alpha^{\mathrm{pub}}$. To be able to compare the results when corruption has two components to the situation when it has a single component, we assume in addition that $\alpha^{\mathrm{pvt}}+\alpha^{\mathrm{pub}}=1$, which implies that $\alpha^{\text {pub }}<1<\alpha^{\text {pvt }}$.

As in Section (2.1), the decision problem reduces to a Markov decision problem with two states, hence the optimal strategy is stationary and denoted by $\left(x_{\beta}^{\mathrm{pub}}, x_{\beta}^{\mathrm{pvt}}\right)$.

The probability $\theta_{\beta}\left(x^{\mathrm{pub}}, x^{\mathrm{pvt}}\right)$ that the incumbent wins elections when her observed levels of corruption at the last period were $x^{\text {pub }}$ and $x^{\text {pvt }}$ is

$\theta_{\beta}\left(x^{\mathrm{pub}}, x^{\mathrm{pvt}}\right):= \begin{cases}1 & \alpha^{\mathrm{pub}} x^{\mathrm{pub}}+\alpha^{\mathrm{pvt}} x^{\mathrm{pvt}}+4 \beta \leq 0, \\ 1-\alpha^{\mathrm{pub}} x^{\mathrm{pub}}-\alpha^{\mathrm{pvt}} x^{\mathrm{pvt}}-4 \beta & 0 \leq \alpha^{\mathrm{pub}} x^{\mathrm{pub}}+\alpha^{\mathrm{pvt}} x^{\mathrm{pvt}}+4 \beta \leq 1, \\ 0 & 1 \leq \alpha^{\mathrm{pub}} x^{\mathrm{pub}}+\alpha^{\mathrm{pvt}} x^{\mathrm{pvt}}+4 \beta .\end{cases}$

The total expected discounted payoff of the incumbent when she uses the stationary strategy $\left(x^{\mathrm{pub}}, x^{\mathrm{pvt}}\right)$ is given by

$$
v_{\beta}\left(x^{\mathrm{pub}}, x^{\mathrm{pvt}}\right):=\frac{x^{\mathrm{pub}}+x^{\mathrm{pvt}}}{1-\delta \theta_{\beta}\left(x^{\mathrm{pub}}, x^{\mathrm{pvt}}\right)} .
$$

We look for corruption levels $\left(x_{\beta}^{\mathrm{pub}}, x_{\beta}^{\mathrm{pvt}}\right) \in\left[0, \frac{1}{2}\right]^{2}$ that maximize the total expected discounted payoff. Clearly, if the incumbent is impatient, then she will steal the maximal possible amount as long as she is in office.

We show in Claim (2) below that for plausible values of $\delta$, the private component of corruption is more responsive to electoral competition than the public component. This is intuitively clear: if the only discipline on incumbent theft comes from re-election concerns, then what matters more to voters should affect incumbent behavior much more than what voters care less about. This is what we show in Claim (2) below.

To state the result we use the following definitions. A function $\beta \mapsto f(\beta)$ has a $U$-shape if there are $\beta_{0}<\beta_{1}$ such that $f$ is constant for every $\beta<\beta_{0}$ and every $\beta>\beta_{1}$, and is monotonic decreasing in the interval $\left[\beta_{0}, \beta_{1}\right]$. We divide the predicted behavior into two cases: the majority is with the incumbent (the negative region $\beta \in[-1,0]$ ) or with the 
challenger (the positive region $\beta \in[0,1]$ ). In the former case, higher competition is bad news for the incumbent, while in the latter case it is good news for the incumbent ${ }^{13}$.

It turns out that in the model with two types of corruption, the optimal corruption level of each component in each region is either the constant $\frac{1}{2}$ (maximal level of corruption, unaffected by competition), monotonic nonincreasing (competition lowers corruption), or has a U-shape. The exact shape of the optimal level of corruption depends on the discount factor $\delta$ and on the significance that the voters assign to each component $\alpha^{\mathrm{pub}}$ and $\alpha^{\mathrm{pvt}}$. Below we present Claim (2).

Claim 2 There exist $\delta_{0}<\delta_{1}<\delta_{2}$ such that the optimal levels of corruption $\left(x_{\beta}^{\mathrm{pub}}, x_{\beta}^{\mathrm{pvt}}\right)$ is as follows:

\begin{tabular}{c||c|c||c|c}
\multicolumn{1}{c||}{} & \multicolumn{2}{c|}{ Electoral advantage with incumbent } & \multicolumn{2}{c}{ Electoral advantage with challenger } \\
discount factor & $x_{\beta}^{\mathrm{pub}}$ & $x_{\beta}^{\mathrm{pvt}}$ & $x_{\beta}^{\mathrm{pub}}$ & $x_{\beta}^{\mathrm{pvt}}$ \\
\hline \hline$\delta<\delta_{0}$ & $\frac{1}{2}$ & $\frac{1}{2}$ & $\frac{1}{2}$ & $\frac{1}{2}$ \\
\hline$\delta_{0}<\delta<\delta_{1}$ & $\frac{1}{2}$ & U-shape & $\frac{1}{2}$ & $\frac{1}{2}$ \\
\hline$\delta_{1}<\delta<\delta_{2}$ & $\frac{1}{2}$ & nonincreasing & $\frac{1}{2}$ & nonincreasing \\
\hline$\delta_{2}<\delta$ & U-shape & U-shape or & $\frac{1}{2}$ & $\frac{1}{2}$ or \\
& & nonincreasing & & nonincreasing \\
\hline
\end{tabular}

The proof of Claim (2), as well as the explicit shape of the optimal strategy for all $\delta$ appear in the Appendix.

As Claim (2) states, the optimal strategy depends on the discount factor of the incumbent. What are plausible discount rates in our setting? Recent work on uncovering personal discount rates in large samples (see Warner and Pleeter (2001), Brown et al. (2010), and the references therein) has documented annual discount rates between 0.1 and 0.2 (with corresponding discount factors between 0.8 and 0.9 ). Based on these estimates the discount factor for a five-year term should be between 0.4 and 0.6. In the Appendix we show that $\delta_{2}=\frac{2}{2+\alpha^{\text {pub }}}>\frac{2}{3}$. This implies, in particular, that the last row of the table in Claim 2 (in which we obtain non-monotonicity in both components), corresponds to very patient incumbents. In contrast, the second row in this table, in which non-monotonicity occurs only in the private component, while $x^{\text {pub }}=\frac{1}{2}$, corresponds to two cases:

- $\delta \in\left[\frac{2}{4+\alpha^{\mathrm{pvt}}-\alpha^{\mathrm{pub}}}, \frac{2}{2+\alpha^{\mathrm{pub}}}\right]$ when $1 \leq \alpha^{\mathrm{pvt}} \leq \frac{4}{3}$.

\footnotetext{
${ }^{13}$ E.g. the function $\beta \mapsto x_{\beta}^{*}$ that is depicted in Figure 1 has a U-shape in the negative region and is the constant 1 in the positive region.
} 
- $\delta \in\left[\frac{2}{4+\alpha^{\mathrm{pvt}}-\alpha^{\mathrm{pub}}}, \frac{2}{2+\alpha^{\mathrm{pvt}}}\right]$ when $\frac{4}{3} \leq \alpha^{\mathrm{pvt}}$.

In both cases the U-shape is obtained for a large range of plausible discount factors. When $1 \leq \alpha^{\text {pvt }} \leq \frac{4}{3}$, the smallest interval such that $\delta \in\left[\frac{2}{4+\alpha^{\mathrm{pvt}}-\alpha^{\mathrm{pub}}}, \frac{2}{2+\alpha^{\mathrm{pub}}}\right]$ is $\left[\frac{1}{2}, \frac{2}{3}\right]$ while the largest such interval is $\delta \in\left[\frac{3}{7}, \frac{3}{4}\right]$. When $\frac{4}{3} \leq \alpha^{\mathrm{pvt}}$, the smallest interval such that

$\delta \in\left[\frac{2}{4+\alpha^{\mathrm{pvt}}-\alpha_{\mathrm{pub}}}, \frac{2}{2+\alpha^{\mathrm{pvt}}}\right]$ is $\left[\frac{1}{3}, \frac{1}{2}\right]$ while the largest such interval is $\delta \in\left[\frac{3}{7}, \frac{3}{4}\right]$. Both are consistent with the empirically observed discount factors between 0.4 and 0.6. For these reasons, we focus on the second row of the table in our empirical section.

Below we summarize our main findings from the model:

1. When electoral bias is towards the incumbent, average corruption follows a U-shape: corruption level is high when competition is either very low or very high, while in the intermediate range corruption is decreasing with competition.

2. When electoral bias is against the incumbent, corruption remains high regardless of competition.

3. The magnitude of corruption in the public component is never lower than in the private component, and for a wide range of parameters it is strictly higher.

4. For a wide range of parameters, the non-linearity in corruption relative to competition is driven by the private component of corruption.

\section{Background: The National Rural Employment Guarantee Program}

The National Rural Employment Guarantee Act (Ministry of Rural Development, Government of India (2005)) mandates the provision of 100 days of manual work on publicly funded projects to rural households in India. The Act envisions a rights based approach rural adults can demand work at a mandated minimum wage. The program was initially implemented in the country's poorest 200 districts in February 2006, with 130 additional districts added in the next stage (2007) and national coverage thereafter (2008). In 2011-12, the Act provided employment to almost 40 million households at an annual expenditure of more than $\$ 8$ billion, making it one of the most ambitious poverty alleviation programs in India to date.

While the primary objective of the program is social protection through the provision of employment, it also aims to create durable assets for the community, as a whole, and 
for socio-economically disadvantaged individuals (e.g., irrigation canals, ponds for water conservation, development of land for cultivation by socially disadvantaged groups and other rural infrastructure). Unlike the typical government transfer programs which either provide pure public goods (e.g., road construction) or pure private goods (e.g., subsidized foodgrains and school meals), the NREGA is unique in delivering both types of goods. Thus, the NREGA stipulates that at least 60 percent of the program expenditures be on labor (viz. wage payments) and the remainder on the materials used for the rural projects. Another novel feature of the NREGA, unlike all other public programs in India, is mandated audits of program expenditures at the village level.

Grass roots institutions, i.e., directly elected village, sub-district, and district level governments (or panchayats) under India's decentralized system of governance (the Panchayati Raj system conceived by the 73rd amendment to the Indian constitution in 1992) have a leading role in the planning and implementation of NREGA works. In particular, the portfolio of projects to be implemented under the program has to be prepared by and follow the priority expressed by an assembly of residents of a village council or Gram Panchayat (GP), a collection of 3-4 villages. The leader of the GP, the sarpanch, is directly elected by its adult residents and holds the overall responsibility for decisions made by the GP. Further, at least 50 percent of the NREGA projects have to be implemented by the GP (and the remainder by the upper two tiers of the panchayat). We will empirically test the predictions of our theory using data on elections to the position of the GP head (henceforth, sarpanch) and the implementation of the NREGA at the GP level.

\subsection{The administration of NREGA projects in Andhra Pradesh}

This paper uses data from the state of Andhra Pradesh (AP) for the period 2006 to $2010 .{ }^{14}$ As of 2011 AP was India's fifth largest state in terms of population (Ministry of Home Affairs, Government of India (2015)) and among the leading states in NREGA implementation due to consistently high generation of NREGA employment and its unique approach to auditing of NREGA projects. AP has vested the audit responsibility within an autonomous arm of its Department of Rural Development. The state has conducted regular and systematic audits of NREGA projects since 2006, unlike other states of India where audits are either not conducted or conducted in an ad-hoc and unsystematic manner. The state, therefore, claims to maintain high levels of accountability and transparency in program implementation. ${ }^{15}$

\footnotetext{
${ }^{14}$ In 2014 Andhra Pradesh was bifurcated into two separate states - Andhra Pradesh and Telangana.

${ }^{15}$ For a fuller account of the genesis and evolution of the AP's social audit model, see Aiyar et al. (2013).
} 
Before turning to the design and conduct of the audits, we discuss here the role of GPs in NREGA implementation in AP. Village councils in AP are typically less autonomous than in some other states of India (Ban and Rao (2008)). But even though the sub-district level bureaucracy holds the over-arching responsibility of NREGA implementation (e.g., project sanctioning and expenditure approvals), the GP maintained a crucial role in managing and executing NREGA projects during the period of our study. ${ }^{16}$ First, the Gram Rozgar Sevak or the Field Assistant (FA), a resident of the GP who assists the village council in NREGA implementation, was appointed on the recommendation of the village council. The FA represents the direct interface of beneficiary households with the program, e.g., maintaining labor records at worksites. Second, the sarpanch selected suppliers of the material inputs to projects implemented under the program and was therefore well positioned to fudge material expenditures in connivance with the technical staff (viz., Assistant Engineers, Technical Assistants, and/or the suppliers) as suggested by anecdotal evidence from the field. The village council and its leader, thus, are accountable for efficient program implementation and the labor and material expenditures on the NREGA projects. Given the scale of the NREGA program, the annual availability of public funds at the grassroots level for public programs increased almost three-fold (from approximately Rs. 50,000 million in 2005 to more than Rs. 140,000 million in 2006 (Afridi (2008)), following the passing of the Act. Consequently, the potential magnitude of pilferage from public funds rose dramatically, as well.

\subsection{The audit process in AP}

The AP audit process is unique, combining a top-down approach with grassroots, beneficiary participation. ${ }^{17}$ The first step in conducting the audit of NREGA projects is a notification to the relevant sub-district (henceforth, mandal) office with reference to the Right to Information obligations and requesting unrestricted access to the records on wage and materials payments by the state's independent audit body. A team, comprising state and district auditors, along with residents of the mandal to be audited (but not of the audited GP to prevent intimidation and ensure that audit outcomes are unbiased) conduct a two-day workshop on NREGA rights and regulations and on how to conduct the audits.

\footnotetext{
${ }^{16}$ Through a Government of Andhra Pradesh order in December 2007, the administrative functions relating to the implementation of all projects under the NREGA were devolved to Panchayati Raj institutions (G.O. Ms. No. 571) (www.rd.ap.gov.in).

${ }^{17}$ As Aiyar and Kapoor Mehta (2015) point out, the audit process in AP resembles a top down audit more than a bottom-up approach.
} 
Following the training, audits are organized in all GPs of the mandal over a week. In each GP, official labor expenses are verified by visiting laborers listed in the worksite logs ("muster-rolls"). Complaints by individuals or groups of beneficiaries and those discovered by the audit team are recorded and attested using a standardized audit report template. ${ }^{18}$ For verification of material expenditure, the audit team is mandated to undertake worksite inspections. Since the verification of material expenditure is typically perceived to be more complex and demanding, the worksite inspections are usually carried out by state and district auditors of the team. The audit process, therefore, is initiated and led by the state but it assimilates local stakeholders into the process of appraising program expenditures.

Once the audits of all GPs have been completed, a mandal level public hearing to discuss the audit findings is organized with mandatory attendance for all implementing officials. Those present often include wage seekers from the villages in the mandal, the audit team, key implementing officials, members of the vigilance cell, elected representatives and a district-level ombudsman (Aiyar et al. (2013)). Complaints are read out, testimonies verified, and accused officials given an opportunity to defend themselves. The scope for frivolous complaints is therefore minimal, if at all.

After the public hearing a decision taken report is created by the officer presiding over the hearing. In this report the responsibility for each confirmed malfeasance is pinned on a program functionary or, as the case may be, on multiple functionaries. ${ }^{19}$ Research suggests, however, that the guilty often escape legal or administrative penalties (Afridi and Iversen (2014)). Systematic and standardized audits were carried out in all 23 districts of the erstwhile state with an average of over two rounds of audits completed per GP between 2006 and 2010.

\section{Data and methodology}

\subsection{Data}

We use four sources of data in this paper. First, official and original audit reports for 100 randomly sampled mandals across eight districts of AP were obtained from the state auditor. ${ }^{20}$ In each randomly chosen mandal, three GPs were selected based on the following

\footnotetext{
${ }^{18}$ The auditors are expected to verify labor records for 100 percent of the beneficiaries. This may not be true in practice.

${ }^{19}$ The audit body has created checks and balances within the audit process such that the program functionaries who are being audited, do not corrupt the auditors themselves.

${ }^{20}$ These eight districts were Mahbubnagar, Medak, Nizamabad, Warangal, and Khammam (north or Telangana region, now part of Telangana state), Anantpur and Kurnool (south or Rayalseema region), and
} 
criteria: the GP which was the administrative headquarter of the mandal, one GP randomly selected from all GPs reserved for a woman sarpanch and one randomly selected from GPs not reserved for a woman sarpanch in that mandal in $2006 .^{21} \mathrm{We}$, thus, randomly sampled 300 GPs for digitizing the NREGA audit findings.

We extracted data from the first round of audits that began in 2006 and until mid$2010 .{ }^{22}$ Panel data of audit report findings were constructed for each sampled GP with an average of over two reports per GP for this period. ${ }^{23}$

The second data source is a primary survey we conducted in all 300 sampled GPs in 2011-12 to collect information on GP and sarpanch characteristics. Retrospective data on the elections to the village council in July 2006 following which new village council members, including the sarpanch, assumed office for a five-year term, were gathered from the elected sarpanch. ${ }^{24}$ Information was obtained on votes received by each contestant in the sarpanch election and their party affiliation. It is worth noting that the timing of this election overlaps with the phasing-in of the NREGA in February, 2006 in AP, giving us the opportunity to study program implementation up to 2010 with the characteristics of the village council and the sarpanch unchanged.

In addition to the above two data sources, official, administrative data on NREGA implementation (viz. program expenditures, employment generated) were collated annually from the website of the Ministry of Rural Development for the financial years 2006-07 to 2011-12 at the GP level. Finally, GP level characteristics on infrastructure and availability of public goods, such as schools, were obtained from the census closest to the GP election - village level census abstracts for 2001.

Tables 1 and 2 summarize our data. In 1, Panel 1 describes the GP's characteristics. The data suggest that the villages in our sample are moderately developed in terms of availability

Guntur (west or coastal region). NREGA was implemented in February 2006 in all these districts, except Kurnool and Guntur, which implemented the program from April, 2007 onwards.

${ }^{21}$ At least third of all village council seats are randomly reserved for a woman sarpanch in AP and across all states in India (viz. Afridi et al. (forthcoming)).

${ }^{22}$ Original audit reports that were missing were supplemented with abridged versions of the audit reports available from the state auditor's website: http://125.17.121.162/SocialAudit/.

${ }^{23}$ Information in the audit reports were coded as follows: each complaint was first classified into labor, material, or worksite facilities related. The former two were further categorized by type. For each complaint we recorded whether any misappropriated amount was mentioned; if yes, the amount was mentioned, otherwise it is missing.

${ }^{24}$ The retrospective election data were corroborated with three other respondents in each GP - the closest losing contestant in terms of proportion of total votes received, a worker of the losing political party, and the GP secretary. The correlation between the margin of victory reported by the elected sarpanch and each of the other three respondents in our survey data varies between 0.95 and 0.97 . 
of public facilities (e.g., medical, communication, and bank facility). 86.4 percent of the sampled villages have paved roads. 28 percent of the sampled villages belong to a GP which is the headquarter of the mandal. Data on the reservation status of the sarpanch position in 2006 shows that 42.7 percent of the sampled GPs were reserved for a woman sarpanch. More than 67 percent of the sarpanch positions were reserved for disadvantaged groups (i.e., scheduled castes (SC), scheduled tribes (ST), or Other Backward Castes (OBCs)).

In Panel 2, we present the individual characteristics of the sarpanch chosen in the 2006 village council elections. 44.5 percent of the elected candidates were affiliated with the Indian National Congress (INC) while 35.8 were affiliated with the Telugu Desam Party (TDP). ${ }^{25}$ This aligns with our theoretical assumption of left (represented by the INC) and right (represented by the TDP, which has often formed coalitions with the right-wing Bhartiya Janata Party)-leaning ideologies. The remaining, approximately 20 percent of candidates, were either affiliated with regional or communist parties (viz. Telangana Rashtra Samithi, Communist Party of India (Marxist)) or were independent candidates. Thus, the two main political parties during the 2006 elections were INC and TDP. Almost 20 percent of the winning candidates had prior political experience, either as a political party worker or in a position in the panchayat. Even though the average number of prior terms in a political office was less than 1 or 0.226 , for the elected sarpanch, 45 percent of them had a close relative who either currently or previously held an office in the panchayat (either at the village, mandal, or district level). In addition, in our survey we gauged the incumbent's perception of voters' bias for or against her by asking the elected sarpanch to estimate her chances of re-election in the forthcoming GP elections. ${ }^{26}$ The average response was 3.77 or "moderate chance of re-election".

The summary statistics on the retrospective sarpanch election data are in Panel 3 of Table 1. The number of contestants in the sarpanch election was a little under 3 , on average. The winning candidate received 20.9 percent more votes, of total votes polled, than her closest contestant. The margin of victory is the difference between the percentage of votes polled in favor of the winning candidate and her closest rival in the election. It is our measure of electoral competition in the empirical analysis.

Panel 1 of Table 2 shows the summary statistics for the audit data for 2006-10, i.e.,

\footnotetext{
${ }^{25}$ Although GP level elections do not require formal party affiliation, candidates typically represent a political party.

${ }^{26}$ The survey question was as follows: Please rank the chances of your being re-elected in the next sarpanch elections in this Gram Panchayat on a scale of 0 to 5: (0) No chance of re-election, (1) Very low, (2) Low, (3) Moderate, (4) High, (5) Almost certain to be re-elected, (999) Can't say/don't know.
} 
over the tenure of the sarpanch elected in a GP in 2006. The total number of audits conducted during this period was 711 or 2.37 audits per GP. The average number of registered irregularities was 5.823 , the majority ( 86.9 percent) of which were related to the private component of NREGA - program benefits that the electorate is likely to care deeply about. Data on rupee amounts of irregularities are missing for many complaints. Nevertheless, to give the reader an idea of the possible extent of leakage we summarize the data on the reported irregularity amount per irregularities for which an amount was reported. This is considerable - Rs. 16,329 in real terms, and much larger for the public component of the program, benefits that voters are more likely to free ride on, than the private component of the NREGA. We provide more details on our private/public classification in the next section.

NREGA expenditures and employment at the GP level are shown for 2006-07 to 201112 in Panel 2 in Table 2. The projects were substantive, with an average cost of over Rs. 1.5 million. The majority of the projects were on water conservation (32.4\%) and on land development. $11.2 \%$ of the projects were on road construction. The NREGA generated substantial employment per year, almost 1700 million person-days or about 25.12 days of employment per individual who demanded work.

\subsection{Methodology}

Our outcome of interest is the number of irregularities, overall and by type, registered across all audits for each GP over the period 2006-10. Specifically, we run the following analysis:

$$
\text { Irregularity }_{j k l}=\alpha_{0}+\alpha_{1} \text { competition }_{j k l}+\alpha_{2} \text { competition }_{j k l}^{2}+\alpha_{3} \mathbf{X}_{j k l},+\eta_{k} D_{k}+\mu_{j k l} \text {, }
$$

where Irregularity $_{j k l}$ is the total number of irregularities over the period 2006-10 in GP $j$ in mandal $k$ in district $l$. The variable competition $j k l$ is defined as 1 less the margin of victory in the sarpanch elections in 2006 (before the audits were conducted). The margin of victory is the difference between the percentage of votes polled in favor of the winning candidate and her closest rival in the election. Hence, if the candidate is unanimously elected, the margin of victory is 1 and the competition variable equals 0. Electoral competition is, therefore, increasing as the magnitude of this variable rises. The square of this variable accounts for any non-linear impact of electoral competition on our measure of corruption. $\mathbf{X}_{j k l}$ is a vector of GP level characteristics that includes the characteristics of the sarpanch

elected in 2006 (for a five year term) such as gender, caste, education, and age, the GP's access to health, education facilities, and its distance from the nearest town. It also includes a dummy variable for whether the GP is the mandal headquarter and separate dummies 
for whether the sarpanch position in 2006 was reserved for an SC, ST, OBC, or woman candidate. $D_{k}$ is a dummy for mandal $k$ to account for mandal level variation in program implementation.

Our theoretical model suggests a non-linear relationship between electoral competition and malfeasance in program expenditures. We should, therefore, expect a negative coefficient $\left(\alpha_{1}\right)$ on competition $_{j k l}$, which would signify that when electoral competition is low, the number of program irregularities decline. A positive coefficient $\left(\alpha_{2}\right)$ on competition $_{j k l}^{2}$, would indicate that as electoral competition rises there is an increase in irregularities related to program implementation. A negative coefficient on the competition variable and a positive one on competition ${ }^{2}$, would together indicate a U-shaped relationship between electoral competition and corruption. This would approximate the main prediction from our theoretical model.

Next, we classify all reported irregularities into two groups - private and public components of corruption. Irregularities related to the private component of the program relate to those that directly affect a beneficiary, e.g., impersonation of worker for wage payment, fudged or incorrect own labor records, non-payment or delay in payment of own wages, bribes paid for due wages, non-provision of work demanded, and poor quality of NREGA asset. The public component irregularities refer to discrepancy in materials payments/receipts, ghost projects, and missing expenditure records related to both labor and materials expenses, i.e., program leakages that are unlikely to personally impact the electorate. By comparing the coefficients obtained on our electoral competition variables, between public and private components of the NREGA, we test our theoretical prediction that corruption is likely to be higher in the private component of a public program.

The above specification identifies the effect of electoral competition on program implementation by taking advantage of variation in the degree of competition across GPs within the same mandal. However, there may be variation in implementation of the program and the level of corruption over the period under study as well as type of irregularities. Moreover, taking advantage of the panel structure of our data by conducting the analysis at the GP-audit level would buy greater power to the analysis due to the resulting larger number of observations.

Our empirical specification, utilizing the panel structure, is given by:

$$
\begin{aligned}
\text { Irregularity jklmt } & =\beta_{0}+\beta_{1} \text { competition }_{j k l}+\beta_{2} \text { competition }_{j k l}+\beta_{3} \mathbf{X}_{j k l}+\beta_{t} \text { Year }_{t} \\
& +\delta_{l t}\left(D_{l} * \text { Year }_{t}\right)+\delta_{m} \text { Audit }_{m}+\delta_{k 0} D_{k}+\epsilon_{j k l m t},
\end{aligned}
$$

where the number of irregularities in GP $j$ in mandal $k$ in district $l$ in audit $m$ at time 
$t$ (Irregularity $_{j k l m t}$ ) is a function of electoral competition (competition ${ }_{j k l}$ ) prior to any audits and $\mathbf{X}_{j k l}$ as outlined in Equation (1) above. In addition, there may exist secular time trends $\left(\right.$ Year $\left._{t}\right)$ and district specific time trends $\left(D_{l} * Y e a r_{t}\right)$ that affect the level of corruption in a GP. Furthermore, we include audit and mandal fixed effects to account for unobservables such as auditor's capacity to detect malfeasance, which may improve with successive audit rounds and the mandal bureaucracy's preferences. Both empirical specifications are used to analyse data for over two rounds of audits in each GP between 2006 and 2010.

Note that since electoral competition is measured in 2006 and program irregularities are audited post the GP elections in 2006, we circumvent the concern that both electoral competition and corruption are determined simultaneously. However, there may exist unobservable, GP level characteristics that impact both electoral competition and NREGA implementation. To the extent that the mandal level bureaucracy holds considerable sway over program execution, accounting for mandal fixed effects in our specification should address much of this concern. ${ }^{27}$

\section{Results}

We first present the estimates from Equation (11) in Table 3. Our main outcomes of interest are the total number of irregularities, total irregularities in the private and the public components of the NREGA which were registered during 2006-10 in each GP. To ensure that our outcome variable is not influenced by the variation in the number of audits across GPs in a mandal, we balance the number and round of audit across GPs within each sampled mandal. ${ }^{28}$ We obtain a sample of 283 GPs for which we were able to obtain data for the full set of controls used in the estimating equation. In Columns 1, 3, and 5 we model a linear relationship between electoral competition and reported irregularities. In Columns 2,4 , and 6 we add the square of electoral competition.

Table 3 shows that the coefficient on electoral competition is positive and insignificant overall (Column 1) and for irregularities in the private component (Column 3) but significant for public related irregularities as shown in Column 5. When we introduce the square term for electoral competition, our U-shaped hypothesis from the theoretical model holds up as

\footnotetext{
${ }^{27}$ NREGA corruption can often be with the tacit approval of and understanding with the mandal level bureaucracy (Aiyar and Kapoor Mehta (2015)).

${ }^{28}$ Balancing the number and rounds of audits at the mandal level reduces the sample to 257 GPs and gives similar results.
} 
suggested by the negative coefficient on electoral competition and the positive coefficient on the squared electoral competition term, albeit insignificant in Columns 2, 4, and 6 . The effect of electoral competition, however, is significant at high levels for the public component of the program as indicated by the significant coefficient on competition ${ }^{2}$ in Column 6. Overall, the direction of the coefficients suggests that electoral competition at low levels reduces reported program irregularities, and as electoral competition rises there is an increase in the number of irregularities.

In Table 4 we conduct the analysis at the GP-audit level, taking advantage of the panel structure of the data. In Columns 1,3 , and 5 we include only mandal fixed effects to make the model comparable with Table 3. Columns 2, 4, and 6 show the results from Equation (12), discussed above. Our results are remarkably consistent with those in Table 3. Overall, the coefficients are insignificant but suggest a non-linear, U-shaped relationship between electoral competition and irregularities. Also, the coefficients are not significantly different between the more parsimonious model that includes only mandal fixed effects and the stricter specification, which accounts for trends and audit fixed effects, as well, across all outcomes. This suggests that secular or district specific trends and audit level unobservables were not correlated with electoral competition and did not play a significant role in uncovering program related malfeasance over time. In the remainder of our analysis we will continue to present the results from equation (12).

In Tables 3 and 4 our outcome included all reported irregularities - those reported by professional auditors and program beneficiaries. However, irregularities registered by the former are less likely to suffer from noise due to personal biases. Beneficiary households that report program irregularities, as part of the bottom-up approach of the audit design, are likely to be subject to threats and intimidation, particularly due to the public announcement of the audit findings. This may affect the irregularity reporting behavior of GP residents and may also be correlated with the level of electoral competition in the GP. Hence to reduce measurement errors and potential reporting biases in the data we conduct the analysis for irregularities reported by the professional auditors alone.

These results, reported in Table 5, show that our concerns are valid. Our results are now more robust and in-line with theoretical predictions, based on objective measures of corruption. Once we restrict the sample to only the number and type of irregularities reported by professional auditors, we find that there is a significant U-shaped relationship between electoral competition and corruption in the private component of the NREGA, as shown in Column 2. While the coefficients are insignificant overall and for irregularities in the public component, they are of the right sign in Column 3. Thus, once we account for 
potential reporting biases, our results suggest that corruption is likely to be U-shaped in the private component but it less likely to respond to electoral competition in the public component of NREGA. Our theoretical results however are conditioned by the type of GP - if the electoral advantage is with the incumbent in a GP, we expect a U-shaped relationship between competition and corruption. If however, the electoral advantage is with the challenger, then corruption remains high and unresponsive to competition. Below we test these predictions.

As indicated in 1, we gauged the incumbent's perception of voters' bias for or against her by asking the incumbent to estimate her chances of re-election in the forthcoming GP elections. ${ }^{29}$ The response of the incumbents to this hypothetical question correlates significantly with the degree of political entrenchment of the sarpanch's family. We define political entrenchment as the number of relatives of the incumbent who have held political positions and the number of years they held those positions. We consider an incumbent's family to be more politically entrenched the higher the average number of years (total years in political office/number of relatives who have held political positions) her relatives were in a political office. The correlation between re-election expectations and political entrenchment is positive and significant at the 5 percent level in our data. We expect the incumbent's political entrenchment to have two effects. First, there should be fewer private component irregularities reported because of the power that the incumbent may have, which would intimidate voters and second, the incumbent would care less about a theft being caught when she is entrenched, and expects to be re-elected with a high probability. Our theoretical model is only about actual rather than reported corruption. We argue that the results support our model. When competition is low and electoral bias is towards the incumbent, then the incumbent has higher incentives to cheat while voters have lower incentives to report irregularities. As competition increases, the incentives to be corrupt decrease until competition is too stiff. On the other hand, voters' incentives to report increase monotonically with competition. Thus, if reporting bias was the main driving force for the result that there is higher corruption when competition is high, it should also show up as lower corruption when competition is low, but that is not what

\footnotetext{
${ }^{29}$ Incumbents in seats reserved for SC/ST/OBC candidates did not anticipate a change in the reservation status of their village council because the state government was expected to continue using the same Census data as in the 2006 elections to determine the eligibility of village councils for caste based reservations on the basis of the population of disadvantaged ethnic groups. Furthermore, our empirical analysis controls for whether a village council seat was currently reserved or not, and for which socio-economic group, to account for any variation in the incumbent's perception of re-election chances.
} 
we observe: we observe a U-shaped relationship. Secondly, if reporting bias was the main driving force, we should observe a significant difference between auditor only based results and aggregate results, but our results are broadly consistent across the two.

Using our self-reported measure of voter bias, we stratify the sample into electoral bias against (reported re-election probability moderate or less) and for (reported re-election probability more than moderate) the incumbent, and estimate Equation (12) using the sample of irregularities reported by professional auditors in Table 6. Our theoretical model suggests that the effect of electoral competition would be significantly non-linear when bias is in favor of the incumbent. This shows up quite starkly in the results in Table 6. The U-shaped, non-linear effect of electoral competition is significant overall and in the private component in the top panel of the table (when bias is in favor of the incumbent) but insignificant in the lower panel (when bias is against the incumbent) across all columns. The results reported in Table 6 suggest that there is significant variation in the total irregularities by its components, as predicted by our model. In Panel 1 of Table 7, we report the relationship between electoral competition and corruption in each type of irregularity by electoral bias. When we break-up the irregularities into its private components, we find that there is a consistent $\mathrm{U}$-shaped relationship between electoral competition and corruption when the bias is in favor of the incumbent. The results are largely insignificant, or do not point consistently in the same direction when the electoral bias is against the incumbent, in the lower panel in Table 7. In Table 8, we find that irrespective of electoral bias, the relationship between the public components and competition is mostly insignificant and not consistently U-shaped, except for the number of missing wage records. ${ }^{30}$

Our findings, thus, suggest that the nature of corruption in public programs may vary depending on the perceived electoral bias of an incumbent when audits are mandated and its findings are made public. When the incumbent perceives that electoral bias is in her favor (which may be due to political entrenchment), there is significant theft from the program. On the other hand, when re-election is perceived to be more difficult, corruption does not seem to respond much to electoral competition, as predicted by our model. On the other hand, when re-election is perceived to be more difficult, corruption does not seem to respond much to electoral competition, as predicted by our model. This suggests that at low levels of electoral competition incumbents pilfer from the private component of the program even though voters care more about this aspect of the program benefits, because

\footnotetext{
${ }^{30}$ Our empirical results are validated when we use official NREGA data, the relationship between electoral competition and annual NREGA expenditures is U-shaped, and conversely, inverted U-shaped for annual NREGA employment. These results are available on request.
} 
re-election probability is high despite the public exposure of corruption. Our results echo Ferraz and Finan (2011) but also nuance the impact of mandated disclosure of fraud in public expenditures.

\section{Conclusions}

In this paper we build a simple game theoretic model to capture the effect of electoral competition on re-election concerns when there is public exposure of corruption through mandated audits of government expenditures. We show that corruption has a non-monotonic relationship with electoral competition. Corruption is higher at very low and very high levels of competition and decreases with competition when competition is intermediate. We also show theoretically that when corruption can be divided into "public" and "private" components, incumbents are more likely to allow maximum corruption in the public component, which does not respond to competition, while the corruption in the private component shows a U-shaped relationship with competition. We use the model's predictions to test our hypotheses using official data on mandated audits of the NREGA projects implemented by village councils in Andhra Pradesh during 2006-10 and data on the elections to the headship of these same village councils in 2006. Our results largely confirm the non-linear relationship between electoral competition and corruption, and that the impact of electoral competition is more responsive in the way we suggest when corruption is in the private component.

Our paper contributes to the literature on the effects of electoral competition on corruption (e.g., Aidt et al. (2011), Booth et al. (2011), Besley et al. (2010), Ferraz and Finan (2011)). We use objective measures of corruption to show that in democracies with weak legal institutions and poor enforcement of laws, while elections do offer an alternative disciplining mechanism, it is a flawed mechanism when the volatility induced by very stiff competition reduces the incentives of political leaders to invest in lowering corruption in the future. In particular, citizens may not care as much about the corruption that is in the public component, even though this is key for development. Our results suggest that over-reliance on democracy to solve the problems of weak institutions is misplaced. Indeed, in the context of India, both Aidt et al. (2011) and Mitra and Shajahan (2015) show how criminality increases in districts with tight elections. They mirror our results even though they focus on violent criminal activities rather than corruption specifically.

Our theoretical model suggests that policies that make incumbents more patient would help reducing corruption. Increasing the frequency of elections is one such policy (see Section (7.2) in the Appendix). On the voters' side, policies that increase awareness of how 
theft from infrastructure projects affect their welfare may help to direct politicians attention to controlling corruption in the public component of government programs.

\section{References}

Acemoglu, D. And M. Jackson (2015): "History, Expectations and Leadership in the evolution of social norms," Review of Economic Studies, 82, 423-456.

Acemoglu, D. And J. A. Robinson (2000): "Political Losers as a Barrier to Economic Development," American Economic Review, 90, 126-130.

- (2006): "Economic Backwardness in Political Perspective," American Political Science Review, 100, 115-131.

Afridi, F. (2008): "Can Community Monitoring Improve the Accountability of Public Officials?" Economic and Political Weekly, 43.

Afridi, F. And V. Iversen (2014): "Social Audits and MGNREGA Delivery: Lessons from Andhra Pradesh," India Policy Forum, 10, 297-341.

Afridi, F., V. Iversen, And M. R. Sharan (forthcoming): "Women political leaders, corruption and learning: Evidence from a large public program in India," Economic Development and Cultural Change, 43.

Aidt, T., M. Golden, And D. Tiwari (2011): "Incumbents and Criminals in the Indian National Legislature," Cambridge Working Papers in Economics 1157, University of Cambridge.

Aiyar, Y. And S. Kapoor Mehta (2015): "Spectators or Participants? Effects of Social Audits in Andhra Pradesh," Economic and Political Weekly, Vol. 50.

Aiyar, Y., S. Kapoor Mehta, and S. SamjiI (2013): "India: Implementing Social Audits," in Public Works as a Safety Net: Design, Evidence and Implementation, ed. by K. Subbarao, C. del Ninno, C. Andrews, and C. Rodrigeuz-Alas, The World Bank.

Ashworth, J., B. Geys, B. Heyndels, And F. Wille (2014): "Competition in the political arena and local government performance," Applied Economics, 46, 2264-2276.

Ban, R. And V. RaO (2008): "Tokenism or Agency? The Impact of Women?s Reservations on Village Democracies in South India," Economic Development and Cultural Change, $56,501-530$. 
Banerjee, A. V. And R. Pande (2007): "Parochial Politics: Ethnic Preferences and Politician corruption," KSG Working Paper No. RWP07-031.

Bardhan, P. And T. T. Yang (2004): "Political Competition in Economic Perspective," mimeo, Development and Comp Systems 0407009, EconWPA.

Besley, T., T. Persson, And D. M. Sturm (2010): "Political Competition, Policy and Growth: Theory and Evidence from the US," The Review of Economic Studies, 77, $1329-1352$.

Blackwell, D. (1962): "Discrete Dynamic Programming," The Annals of Mathematical Statistics, 22, 719-726.

Booth, R., D. Filmer, And J. Rigolini (2011): "Does electoral competition improve accountability?" Working Paper.

Brown, J., Z. Ivković, And S. Weisbenner (2010): "Political Risk and Discount Rates: Evidence from the Croatian Pension System," NBER Retirement Research Center Paper No. NB 10-0\%.

Campante, F. R., D. Chor, And Q.-A. Do (2009): "Instability and the incentives for corruption," Economics and Politics, 21, 42-92.

Ferraz, C. AND F. Finan (2011): "Electoral Accountability and Corruption: Evidence from the audits of local governments," American Economic Review, 101, 1274-1311.

Ministry of Home Affairs, Government of India (2015): "Census of India, 2011," http://censusindia.gov.in/2011-common/censusdataonline.html, accessed: 2016$09-2$.

Ministry of Rural Development, Government of India (2005): "National Rural Employment Guarantee Scheme Act 2005: Report of the second year, April 2006-March 2007," http://nrega.nic.in/nregarpt_eng.pdf, accessed 2016-09-2.

Mitra, S. And A. Shajahan (2015): "Crime, Elections and Political Competition," mimeo, IIM Bangalore.

Munshi, K. And M. Rosenzweig (2015): "Insiders and Outsiders: Local Ethnic Politics and Public Goods Provision," Working Paper 21720, National Bureau of Economic Research. 
Muralidharan, K., P. Neihaus, and S. Sukhtankar (2016): "Building State Capacity: Evidence from biometric smartcards in India," American Economic Review, 106, 2895-2929.

Niehaus, P. And S. Sukhtankar (2013): "Corruption Dynamics: The Golden Goose Effect," American Economic Journal: Economic Policy, 5, 230-69.

Olken, B. A. And R. Pande (2012): "Corruption in Developing Countries," Annual Review of Economics, 4, 479-509.

Persson, T., G. Roland, and G. Tabellini (1997): "Separation of Powers and Political Accountability," The Quarterly Journal of Economics, 112, 1163-1202.

Puterman, M. (2014): Markov Decision Processes: Discrete Stochastic Dynamic Programming, Wiley Interscience.

Svaleryd, H. AND J. Vlachos (2009): "Political rents in a non-corrupt democracy," Journal of Public Economics, 93, 355-372.

Svensson, J. (2005): "Eight Questions about Corruption," Journal of Economic Perspectives, 19, 19-42.

Transparency International (2015): "Transparency International Corruptions Perception Index 2015," https://www.transparency.org/cpi2015/, accessed: 2016-09-2.

Warner, J. T. And S. Pleeter (2001): "The Personal Discount Rate: Evidence from Military Downsizing Programs," American Economic Review, 91, 33-53. 
Table 1: GP, sarpanch and election characteristics (2006)

\begin{tabular}{|c|c|c|c|}
\hline Variable & $\mathbf{N}$ & Mean & Std. Dev. \\
\hline \multicolumn{4}{|l|}{ GP characteristics } \\
\hline Proportion of irrigated area & 294 & 0.243 & 0.233 \\
\hline Population density (per sq. km.) & 296 & 3.431 & 3.727 \\
\hline Distance from town $(\mathrm{km})$ & 296 & 30.372 & 20.158 \\
\hline Medical facility & 294 & 0.830 & 0.376 \\
\hline Communication facility & 294 & 0.918 & 0.274 \\
\hline Bank facility & 294 & 0.374 & 0.485 \\
\hline Middle school & 296 & 0.709 & 0.455 \\
\hline Paved road & 294 & 0.864 & 0.343 \\
\hline Main GP of mandal & 300 & 0.280 & 0.500 \\
\hline Sarpanch seat reserved for woman* & 300 & 0.427 & 0.495 \\
\hline Sarpanch seat reserved for SC/ST* & 300 & 0.306 & 0.460 \\
\hline Sarpanch seat reserved for $\mathrm{OBC}^{*}$ & 300 & 0.370 & 0.484 \\
\hline \multicolumn{4}{|l|}{ Sarpanch characteristics } \\
\hline Age & 299 & 44.686 & 9.957 \\
\hline Male & 299 & 0.532 & 0.500 \\
\hline Illiterate & 299 & 0.110 & 0.314 \\
\hline Secondary schooling complete & 299 & 0.100 & 0.310 \\
\hline Graduate or above degree & 299 & 0.107 & 0.310 \\
\hline Belonging to INC & 299 & 0.445 & 0.498 \\
\hline Belonging to TDP & 299 & 0.358 & 0.480 \\
\hline Have own prior political experience & 297 & 0.195 & 0.397 \\
\hline Prior terms in political office & 296 & 0.226 & 0.643 \\
\hline Relative in panchayat & 300 & 0.450 & 0.498 \\
\hline Self-perceived re-election probability & 287 & 3.770 & 1.442 \\
\hline \multicolumn{4}{|l|}{ GP election characteristics } \\
\hline Number of contestants & 299 & 2.916 & 1.767 \\
\hline $\begin{array}{l}\text { Proportions of votes polled out of total } \\
\text { voters }\end{array}$ & 297 & 0.757 & 0.260 \\
\hline $\begin{array}{l}\text { Proportions of votes received by winning } \\
\text { candidate }\end{array}$ & 297 & 0.566 & 0.173 \\
\hline Margin of victory in election & 297 & 0.209 & 0.275 \\
\hline
\end{tabular}

Notes: GP characteristics from Census, 2001; *reservation data from the State Election Commission; SC/ST - Scheduled Caste/Scheduled Tribe; OBC - Other Backward Castes; INC - Indian National Congress; TDP - Telegu Desam Party; prior political experience is a dummy variable that equals 1 if a prior leadership position was held by the current sarpanch; "prior terms in political office" is the number of terms held previously in any political office; "relative in panchayat" equals 1 if the elected sarpanch has a relative who has ever held office in the panchayat; proportion of votes polled is 0 for a unanimously elected sarpanch; votes received by winning candidate and the margin of victory reported as a proportion of total votes polled. 
Table 2: NREGA audit, expenditure and employment characteristics at GP level by year (2006-10)

\begin{tabular}{lccc}
\hline \hline Variable & N & Mean & Std. Dev. \\
\hline Audit characteristics & & & \\
\hline Total number of irregularities & 711 & 5.823 & 5.299 \\
Private component & 711 & 5.062 & 4.594 \\
Public component & 711 & 0.684 & 1.520 \\
Total amount per irregularity (Rs.) & 581 & $16,329.420$ & $52,862.71$ \\
Private component & 555 & $7,920.136$ & $19,500.840$ \\
Public component & 173 & $119,062.0$ & $488,958.20$ \\
\hline Program characteristics & & & \\
\hline Total expenditure (Rs., millions) & 1416 & 1.531 & 1.699 \\
Proportion of expd. on water conservation & 1396 & 0.324 & 0.305 \\
Proportion of expenditure on rural connectivity & 1416 & 0.112 & 0.201 \\
Total employment (person-days, millions) & 1418 & 1699.256 & 2082.414 \\
Employment as proportion of GP population & 1388 & 7.174 & 20.554 \\
Employment as proportion of GP demand & 1371 & 25.117 & 14.178 \\
\hline \hline
\end{tabular}

Notes: Audit data from official audit reports; amounts are reported per irregularity for which the rupee amount was mentioned in the audit; data on program characteristics from the Ministry of Rural Development (MoRD), Government of India for financial years 2006-07 to 2010-11; amounts and expenditures are in 2006 rupees. 
Table 3: Effect of electoral competition on NREGA irregularities (GP level, 2006-10)

(Professional auditor and beneficiary reported irregularities)

\begin{tabular}{|c|c|c|c|c|c|c|}
\hline & \multicolumn{2}{|c|}{ Total irregularities } & \multicolumn{2}{|c|}{$\begin{array}{c}\text { Irregularities in } \\
\text { private component }\end{array}$} & \multicolumn{2}{|c|}{$\begin{array}{l}\text { Irregularities in } \\
\text { public component }\end{array}$} \\
\hline & $(\mathbf{1})$ & $(2)$ & $(3)$ & $(4)$ & $(5)$ & $(6)$ \\
\hline \multirow[t]{2}{*}{ Electoral competition } & 3.188 & -14.35 & 0.605 & -2.773 & $2.863^{*}$ & -9.116 \\
\hline & $(4.855)$ & $(33.77)$ & $(4.149)$ & $(29.38)$ & $(1.527)$ & $(6.578)$ \\
\hline \multirow[t]{2}{*}{ Electoral competition ${ }^{2}$} & & 11.5 & & 2.215 & & $7.855^{*}$ \\
\hline & & $(22.18)$ & & $(19.11)$ & & $(4.703)$ \\
\hline Mandal FE & $\checkmark$ & $\checkmark$ & $\checkmark$ & $\checkmark$ & $\checkmark$ & $\checkmark$ \\
\hline $\mathrm{N}$ & 283 & 283 & 283 & 283 & 283 & 283 \\
\hline$R^{2}$ & 0.719 & 0.719 & 0.716 & 0.716 & 0.619 & 0.624 \\
\hline
\end{tabular}

Note: The dependent variable is the sum of all irregularities reported in a GP during 2006-10. Number and round of audit balanced across GPs within a mandal. Controls include sarpanch characteristics (age, age square, dummy for secondary education completed, dummy for graduate and above education; dummy for prior political experience, affiliated to INC) GP characteristics (main GP of mandal, medical, communication, banking, paved road, middle school in GP, distance from town, proportion of cultivated area which is irrigated, population density, dummy for SC, ST, OBC, woman reserved sarpanch candidate, sarpanch elected unanimously). Standard errors in parentheses. Significant at ${ }^{*} 10 \%,{ }^{*} 5 \%$, and ${ }^{* * *} 1 \%$. 
Table 4: Effect of electoral competition on NREGA irregularities (GP-audit level, 2006-10) (Professional auditor and beneficiary reported irregularities)

\begin{tabular}{|c|c|c|c|c|c|c|}
\hline & \multicolumn{2}{|c|}{ Total Irregularities } & \multicolumn{2}{|c|}{$\begin{array}{c}\text { Irregularities in } \\
\text { private component }\end{array}$} & \multicolumn{2}{|c|}{$\begin{array}{l}\text { Irregularities in } \\
\text { public component }\end{array}$} \\
\hline & (1) & $(2)$ & (3) & $(4)$ & $(5)$ & $(6)$ \\
\hline \multirow[t]{2}{*}{ Electoral competition } & -4.597 & -4.662 & 0.302 & 0.218 & -3.860 & -3.800 \\
\hline & $(12.55)$ & $(12.80)$ & (10.90) & $(11.11)$ & $(2.474)$ & $(2.534)$ \\
\hline \multirow[t]{2}{*}{ Electoral competition $^{2}$} & 4.070 & 4.052 & 0.0318 & 0.0425 & $3.315^{*}$ & $3.276^{*}$ \\
\hline & $(8.143)$ & $(8.304)$ & $(7.009)$ & $(7.145)$ & $(1.739)$ & $(1.777)$ \\
\hline Mandal FE & $\checkmark$ & $\checkmark$ & $\checkmark$ & $\checkmark$ & $\checkmark$ & $\checkmark$ \\
\hline Year FE & & $\checkmark$ & & $\checkmark$ & & $\checkmark$ \\
\hline Audit FE & & $\checkmark$ & & $\checkmark$ & & $\checkmark$ \\
\hline District $\mathrm{x}$ Year FE & & $\checkmark$ & & $\checkmark$ & & $\checkmark$ \\
\hline $\mathrm{N}$ & 677 & 677 & 677 & 677 & 677 & 677 \\
\hline$R^{2}$ & 0.361 & 0.430 & 0.392 & 0.452 & 0.259 & 0.306 \\
\hline
\end{tabular}

Note: The dependent variable is the number of irregularities in each GP in an audit. Controls as elucidated in Table 3. Standard errors, clustered at the GP level, reported in parentheses. Significant at ${ }^{*} 10 \%, * * 5 \%$, and $* * * 1 \%$. 
Table 5: Effect of electoral competition on NREGA irregularities (GP level, 2006-10) (Professional auditor and beneficiary reported irregularities)

\begin{tabular}{|c|c|c|c|}
\hline & Total irregularities & $\begin{array}{c}\text { Irregularities in private } \\
\text { component }\end{array}$ & Irregularities in public component \\
\hline & $(1)$ & $(2)$ & (3) \\
\hline \multirow[t]{2}{*}{ Electoral competition } & 1.625 & $-5.489 * *$ & -1.057 \\
\hline & $(11.82)$ & $(2.656)$ & $(1.556)$ \\
\hline \multirow[t]{2}{*}{ Electoral competition ${ }^{2}$} & 0.0456 & $3.214^{*}$ & 0.798 \\
\hline & $(7.801)$ & $(1.662)$ & $(1.064)$ \\
\hline $\mathrm{N}$ & 635 & 635 & 635 \\
\hline$R^{2}$ & 0.421 & 0.267 & 0.317 \\
\hline
\end{tabular}

Note: Controls as elucidated in Table 3, including mandal, audit, year fixed effects, and district specific trends. Standard errors, clustered at the GP level, reported in parentheses. Significant at $* 10 \%, * * 5 \%$, and ${ }^{* * *} 1 \%$. 
Table 6: Effect of electoral competition on NREGA irregularities by electoral bias (GP-audit level, 2006-10)( Professional auditor reported irregularities)

\begin{tabular}{lccc}
\hline \hline & All & Private & Public \\
\hline & $(1)$ & $(2)$ & $(3)$ \\
\hline \multirow{2}{*}{ Electoral competition } & & Electoral bias in favor of incumbent & \\
\cline { 2 - 4 } & $-110.8^{* *}$ & $-40.12^{* * *}$ & 7.903 \\
Electoral competition ${ }^{2}$ & $(46.79)$ & $(8.584)$ & $(6.095)$ \\
& $73.03^{* *}$ & $23.08^{* * *}$ & -3.483 \\
\hline$R^{2}$ & $(28.03)$ & $(5.338)$ & $(3.739)$ \\
$N$ & 0.654 & 0.505 & 0.446 \\
& 250 & 250 & 250 \\
\cline { 2 - 4 } & & Electoral bias against incumbent & -1.822 \\
Electoral competition & -5.450 & & $(4.243)$ \\
& $(25.73)$ & 5.647 & 0.749 \\
Electoral competition ${ }^{2}$ & 1.325 & $(4.070)$ & $(2.790)$ \\
\hline$R^{2}$ & $(15.83)$ & -3.170 & 0.407 \\
$N$ & 0.527 & $(2.618)$ & 363 \\
\hline Note: Controls as elucidated in Table 3, including mandal, audit, year fixed effects, and district specific trends. Standard errors, clustered at the GP level,
\end{tabular}


Table 7: Effect of electoral competition on irregularities in the private component by electoral bias (GP-audit level, 2006-10) (Professional auditor reported irregularities)

\begin{tabular}{|c|c|c|c|c|c|c|}
\hline \multicolumn{7}{|c|}{ Private component related irregularities } \\
\hline & $\begin{array}{l}\text { Impersonations } \\
\text { in wage payments }\end{array}$ & $\begin{array}{l}\text { Irregularities } \\
\text { in own labor } \\
\text { records }\end{array}$ & $\begin{array}{l}\text { Non payment/ } \\
\text { delay of wages }\end{array}$ & $\begin{array}{c}\text { Payments of } \\
\text { bribes to receive } \\
\text { due wages }\end{array}$ & $\begin{array}{l}\text { Non-provision } \\
\text { of work }\end{array}$ & $\begin{array}{c}\text { Poor quality } \\
\text { of asset }\end{array}$ \\
\hline & $(1)$ & $(2)$ & (3) & $(4)$ & $(5)$ & $(6)$ \\
\hline & \multicolumn{6}{|c|}{ Electoral bias in favour of incumbent } \\
\hline \multirow[t]{2}{*}{ Electoral competition } & $-7.494^{* * *}$ & $-9.220^{* * *}$ & -1.875 & -9.068 & 0.619 & $-13.08^{* * *}$ \\
\hline & $(2.622)$ & $(2.374)$ & $(1.147)$ & $(6.244)$ & $(1.422)$ & $(2.287)$ \\
\hline \multirow[t]{2}{*}{ Electoral competition ${ }^{2}$} & $4.556^{* * *}$ & $4.911^{* * *}$ & $1.417^{* *}$ & 5.435 & -0.802 & $7.567^{* * *}$ \\
\hline & $(1.645)$ & $(1.391)$ & $(0.670)$ & $(3.886)$ & $(0.886)$ & $(1.304)$ \\
\hline$R^{2}$ & 0.548 & 0.534 & 0.420 & 0.353 & 0.483 & 0.514 \\
\hline \multirow[t]{2}{*}{$\mathrm{N}$} & 250 & 250 & 250 & 250 & 250 & 250 \\
\hline & \multicolumn{6}{|c|}{ Electoral bias against incumbent } \\
\hline \multirow[t]{2}{*}{ Electoral competition } & $4.667^{* *}$ & 3.644 & 1.865 & -3.028 & $-1.347^{* * *}$ & -0.154 \\
\hline & $(2.281)$ & $(2.410)$ & $(1.387)$ & $(1.981)$ & $(0.507)$ & $(1.781)$ \\
\hline \multirow[t]{2}{*}{ Electoral competition ${ }^{2}$} & $-3.301^{* *}$ & -1.824 & -1.061 & $2.140^{*}$ & $0.817^{* * *}$ & 0.0599 \\
\hline & $(1.474)$ & $(1.545)$ & $(0.864)$ & $(1.286)$ & $(0.306)$ & $(1.155)$ \\
\hline$R^{2}$ & 0.413 & 0.383 & 0.301 & 0.376 & 0.534 & 0.364 \\
\hline $\mathrm{N}$ & 363 & 363 & 363 & 363 & 363 & 363 \\
\hline
\end{tabular}

Note: Controls as elucidated in Table 3, including mandal, audit, year fixed effects, and district specific trends. Standard errors, clustered at the GP level, reported in parentheses. Significant at ${ }^{*} 10 \%, * * 5 \%$, and ${ }^{* * *} 1 \%$. 
Table 8: Effect of electoral competition on irregularities in the public component by electoral bias (GP-audit level, 2006-10) (Professional auditor reported irregularities)

\begin{tabular}{|c|c|c|c|c|}
\hline \multicolumn{5}{|c|}{ Public component related irregularities } \\
\hline & $\begin{array}{l}\text { Non-provision of } \\
\text { wage records }\end{array}$ & $\begin{array}{c}\text { Non-provision } \\
\text { of materials related } \\
\text { records }\end{array}$ & Ghost project & $\begin{array}{c}\text { Discrepancy in } \\
\text { materials payments } \\
\text { receipts }\end{array}$ \\
\hline & $(1)$ & $(2)$ & $(3)$ & $(4)$ \\
\hline & \multicolumn{4}{|c|}{ Electoral bias in favor of incumbent } \\
\hline \multirow[t]{2}{*}{ Electoral Competition } & $-5.531^{*}$ & 0.424 & $3.748^{*}$ & $9.261^{* *}$ \\
\hline & $(3.215)$ & $(1.787)$ & $(1.944)$ & $(3.793)$ \\
\hline \multirow[t]{2}{*}{ Electoral Competition ${ }^{2}$} & $3.225^{*}$ & -0.298 & $-2.350^{* *}$ & $-4.061^{*}$ \\
\hline & $(1.941)$ & $(1.117)$ & $(1.155)$ & $(2.259)$ \\
\hline$R^{2}$ & 0.432 & 0.442 & 0.394 & 0.412 \\
\hline \multirow[t]{2}{*}{$\mathrm{N}$} & 250 & 250 & 250 & 250 \\
\hline & \multicolumn{4}{|c|}{ Electoral bias against incumbent } \\
\hline \multirow[t]{2}{*}{ Electoral Competition } & -2.236 & $2.351^{* *}$ & -3.587 & 1.651 \\
\hline & $(1.751)$ & $(1.101)$ & $(2.411)$ & $(3.430)$ \\
\hline \multirow[t]{2}{*}{ Electoral Competition ${ }^{2}$} & 1.388 & $-1.474^{* *}$ & 1.805 & -0.970 \\
\hline & $(1.139)$ & $(0.675)$ & $(1.540)$ & $(2.274)$ \\
\hline$R^{2}$ & 0.455 & 0.378 & 0.379 & 0.332 \\
\hline $\mathrm{N}$ & 363 & 363 & 363 & 363 \\
\hline
\end{tabular}

Note: Controls as elucidated in Table 3, including mandal, audit, year fixed effects, and district specific trends. Standard errors, clustered at the GP level, reported in parentheses. Significant at $* 10 \%, * * 5 \%$, and $* * * 1 \%$. 


\section{APPENDIX}

\subsection{Proofs}

Claim (1): The optimal level of corruption for the incumbent is given by:

- If $\beta \leq-\frac{1}{4}$, then $x_{\beta}^{*}=1$.

- If $-\frac{1}{4} \leq \beta \leq-\frac{1-\delta}{4 \delta}$, then $x_{\beta}^{*}=-4 \beta$.

- If $-\frac{1-\delta}{4 \delta} \leq \beta$, then $x_{\beta}^{*}=1$.

Proof. Suppose that $\beta \leq-\frac{1}{4}$. Then the margin of victory for the incumbent is high, and even if she steals the full amount she wins elections for sure. It follows that $x_{\beta}^{*}=1$ and $v_{\beta}(x)=\frac{1}{1-\delta}$ for $\beta \leq-\frac{1}{4}$.

Suppose that $\beta \geq \frac{1}{4}$. Then the margin of victory for the challenger is high, the incumbent will lose elections whatever amount she steals, and therefore her optimal behavior is to steal everything and lose the election. It follows that $x_{\beta}^{*}=1$ and $v_{\beta}(x)=1$ for $\beta \geq \frac{1}{4}$.

Suppose that $-\frac{1}{4} \leq \beta \leq 0$. On the interval $x \in[0,-4 \beta]$ we have $\theta(x)=1$, so that $v_{\beta}(x)=\frac{x}{1-\delta}$. It follows that the function $x \mapsto v_{\beta}(x)$ is monotonically increasing on the interval $[0,-4 \beta]$.

Suppose that $0 \leq \beta \leq \frac{1}{4}$. On the interval $x \in[1-4 \beta, 1]$ we have $\theta(x)=0$, so that $v_{\beta}(x)=x$. In

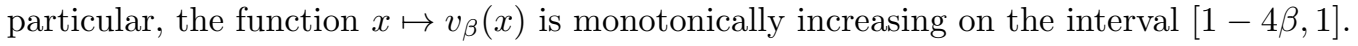

Consider now the interval in which $\theta_{\beta}(x)=1-x_{t}-4 \beta$; that is, either $-\frac{1}{4} \leq \beta \leq 0$ and $x \in[-4 \beta, 1]$, or $0 \leq \beta \leq \frac{1}{4}$ and $x \in[0,1-4 \beta]$. In this case, $v_{\beta}(x)=\frac{x}{1-\delta(1-x-4 \beta)}$ and the derivative of $v_{\beta}$ is

$$
v_{\beta}^{\prime}(x)=\frac{1-\delta+4 \delta \beta}{(1-\delta(1-x-4 \beta))^{2}} .
$$

It follows that on the interval in question, the function $v_{\beta}$ is increasing if $\beta>-\frac{1-\delta}{4 \delta}$, is decreasing if $\beta<-\frac{1-\delta}{4 \delta}$, and is constant if $\beta=-\frac{1-\delta}{4 \delta}$.

If $\beta>-\frac{1-\delta}{4 \delta}$, then the function $x \mapsto v_{\beta}(x)$ is increasing in the interval $x \in[0,1]$, and it is optimal for the incumbent to steal $x_{\beta}^{*}=1$.

If $\beta<-\frac{1-\delta}{4 \delta}$, then in particular $\beta$ is negative, the function $x \mapsto v_{\beta}(x)$ is increasing up to $-4 \beta$ and decreasing after $-4 \beta$, so that its maximum is attained at $x=-4 \beta$.

Before proving Claim (2) we prove the following lemma.

Lemma 1 The optimal amount to steal is as follows.

(A) If $\delta \leq \frac{2}{2+\alpha^{\mathrm{pub}}}$, then $x_{\beta}^{\mathrm{pub}}=\frac{1}{2}$ for every $\beta$.

In addition,

(A.1) If $\delta \leq \frac{2}{4+\alpha^{\mathrm{pvt}}-\alpha^{\mathrm{pub}}}$ then $x_{\beta}^{\mathrm{pvt}}=\frac{1}{2}$ for every $\beta$. 
(A.2) If $\frac{2}{4+\alpha^{\mathrm{pvt}}-\alpha^{\mathrm{pub}}} \leq \delta \leq \frac{2}{2+\alpha^{\mathrm{pvt}}}$ then

$$
x_{\beta}^{\mathrm{pvt}}= \begin{cases}\frac{1}{2} & \beta \leq-\frac{1}{4}, \\ -\frac{4 \beta+\frac{\alpha^{\mathrm{pub}}}{2}}{\alpha^{\mathrm{pvt}}} & -\frac{1}{4} \leq \beta \leq-\frac{1-\delta}{4 \delta}+\frac{\alpha^{\mathrm{pvt}}-\alpha^{\mathrm{pub}}}{8}, \\ \frac{1}{2} & -\frac{1-\delta}{4 \delta}+\frac{\alpha^{\mathrm{pvt}}-\alpha^{\mathrm{pub}}}{8} \leq \beta .\end{cases}
$$

(A.3) If $\frac{2}{2+\alpha^{\mathrm{pvt}}} \leq \delta \leq \frac{2}{2+\alpha^{\mathrm{pub}}}$ then

$$
x_{\beta}^{\mathrm{pvt}}= \begin{cases}\frac{1}{2} & \beta \leq-\frac{1}{4}, \\ -\frac{4 \beta+\frac{\alpha^{\mathrm{pub}}}{2}}{\alpha^{\mathrm{pvt}}} & -\frac{1}{4} \leq \beta \leq-\frac{\alpha^{\mathrm{pub}}}{8} \\ 0 & -\frac{\alpha^{\mathrm{pub}}}{8} \leq \beta \leq-\frac{1-\delta}{4 \delta}+\frac{\alpha^{\mathrm{pvt}}-\alpha^{\mathrm{pub}}}{8} \\ \frac{1}{2} & -\frac{1-\delta}{4 \delta}+\frac{\alpha^{\mathrm{pvt}}-\alpha^{\mathrm{pub}}}{8} \leq \beta .\end{cases}
$$

(B) If $\delta \geq \frac{2}{2+\alpha^{\mathrm{pub}}}$, then $x_{\beta}^{\mathrm{pub}}$ and $x_{\beta}^{\mathrm{pvt}}$ are given by the following table:

\begin{tabular}{l|l|l} 
Interval & $x_{\beta}^{\mathrm{pub}}$ & $x_{\beta}^{\mathrm{pvt}}$ \\
\hline$\beta \leq-\frac{1}{4}$ & $\frac{1}{2}$ & $\frac{1}{2}$ \\
$-\frac{1}{4} \leq \beta \leq-\frac{\alpha^{\mathrm{pub}}}{8}$ & $\frac{1}{2}$ & $-\frac{4 \beta+\frac{\alpha^{\mathrm{pub}}}{2}}{\alpha^{\mathrm{pvt}}}$ \\
$-\frac{\alpha^{\mathrm{pub}}}{8} \leq \beta \leq-\frac{1-\delta}{4 \delta}$ & $-\frac{4 \beta}{\alpha^{\mathrm{pub}}}$ & 0 \\
$-\frac{1-\delta}{4 \delta} \leq \beta \leq-\frac{1-\delta}{4 \delta}+\frac{\alpha^{\mathrm{pvt}}-\alpha^{\mathrm{pub}}}{8}$ & $\frac{1}{2}$ & 0 \\
$-\frac{1-\delta}{4 \delta}+\frac{\alpha^{\mathrm{pvt}}-\alpha^{\mathrm{pub}}}{8} \leq \beta$ & $\frac{1}{2}$ & $\frac{1}{2}$
\end{tabular}

Denote

$$
\underline{\beta}(\delta):=-\frac{1-\delta}{4 \delta}+\frac{\alpha^{\mathrm{pvt}}-\alpha^{\mathrm{pub}}}{8} .
$$

This is the threshold of $\beta$ where $x_{\beta}^{\mathrm{pvt}}$ jumps up to $\frac{1}{2}$ as $\beta$ increases. The graph of $x_{\beta}^{\mathrm{pvt}}$ in Case (A.3) appears in Figure 2 and the graph of both $x_{\beta}^{\mathrm{pub}}$ and $x_{\beta}^{\mathrm{pvt}}$ in Case (B) appears in Figure 3.

Figure 2: Optimal corruption of private good for different levels of electoral competition; Case (A.3) of Claim (2). Corruption of private good $\left(x_{\beta}^{\mathrm{pvt}}\right)$

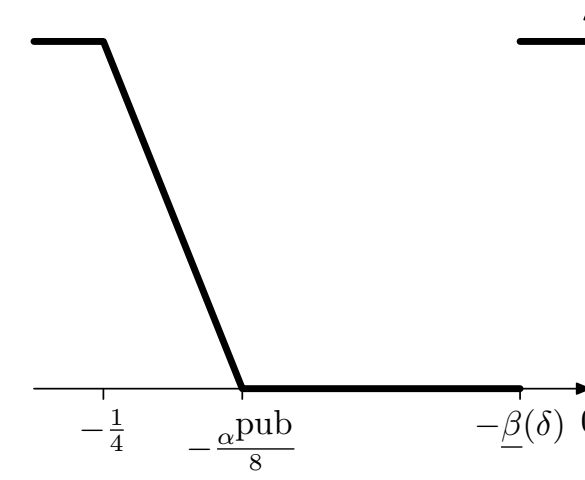

Electoral Advantage with Incumbent

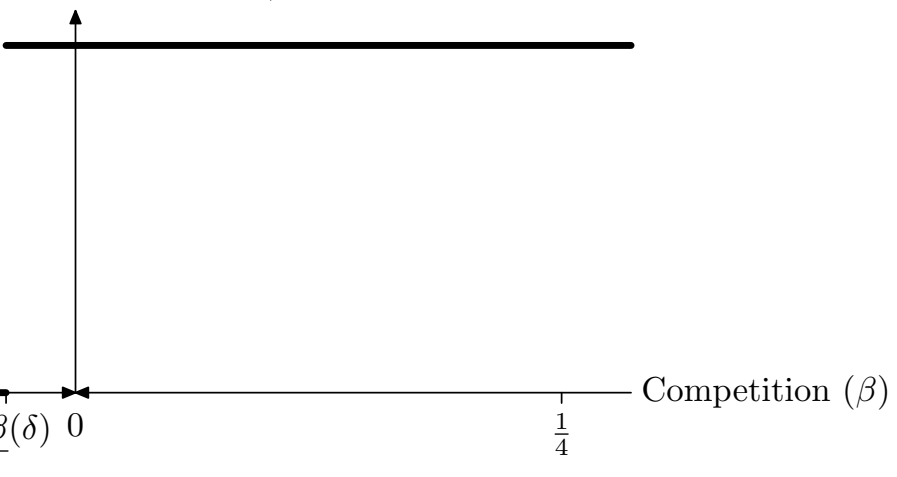

Electoral Advantage with Challenger 
Figure 3: Optimal corruption of private good for different levels of electoral competition; Case (B) of Claim (2). The dark line is $x_{\beta}^{\mathrm{pvt}}$; the dotted line is $x_{\beta}^{\mathrm{pub}}$.

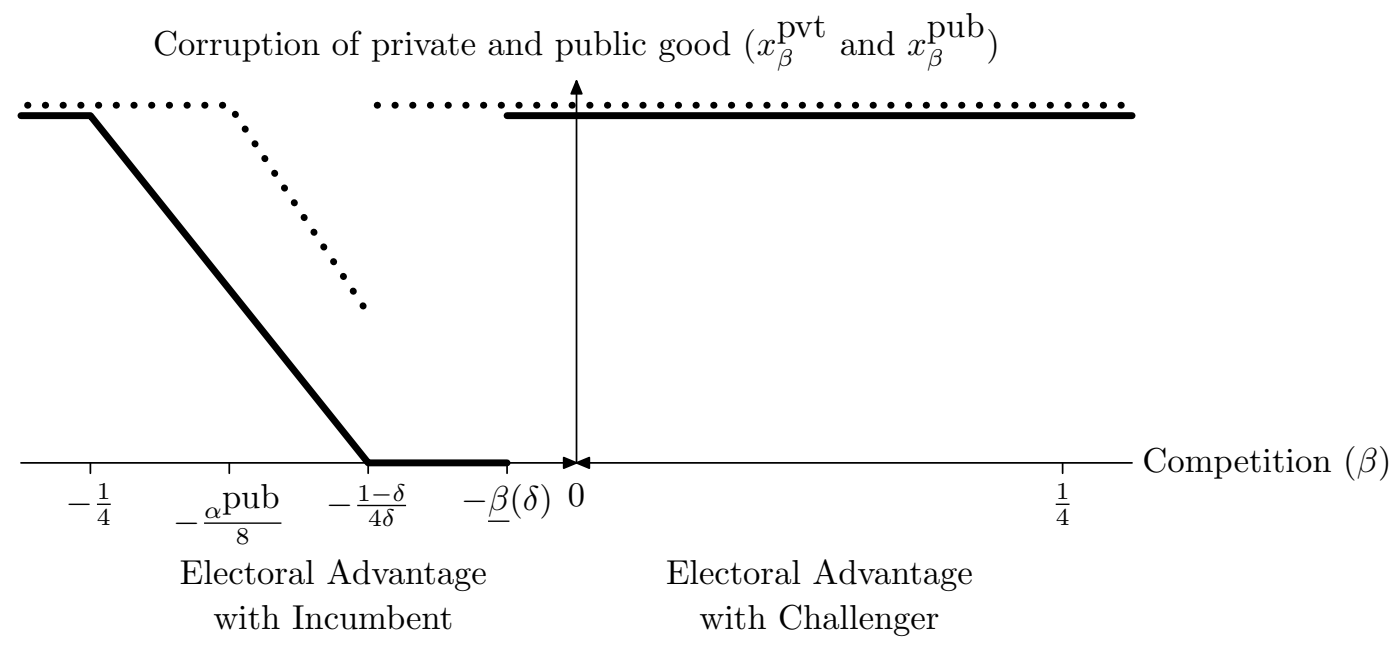

Proof. If the incumbent increases $x^{\mathrm{pub}}$ and decreases $x^{\mathrm{pvt}}$ by the same amount, then the sum $x^{\text {pub }}+x^{\text {pvt }}$ does not change, while the probability of winning elections increases because $\alpha^{\text {pub }}<\alpha^{\text {pvt }}$. Since $v_{\beta}\left(x^{\mathrm{pub}}, x^{\mathrm{pvt}}\right)=\frac{x^{\mathrm{pub}}+x^{\mathrm{pvt}}}{1-\delta \theta_{\beta}\left(x^{\mathrm{pub}}, x^{\mathrm{pvt}}\right)}$ this implies that by this change the incumbent increases her total gain. Formally, for every $x^{\text {pub }}<\frac{1}{2}$, every $x^{\text {pvt }}>0$, and every $\varepsilon>0$ that is at most both $x^{\text {pvt }}$ and $\frac{1}{2}-x^{\mathrm{pub}}$, we have $v_{\beta}\left(x^{\mathrm{pub}}, x^{\mathrm{pvt}}\right)<v_{\beta}\left(x^{\mathrm{pub}}+\varepsilon, x^{\mathrm{pvt}}-\varepsilon\right)$. This implies that $x_{\beta}^{\mathrm{pub}}=\frac{1}{2}$ or $x_{\beta}^{\mathrm{pvt}}=0$ (or both). We will calculate the optimal $x^{\mathrm{pvt}}$ for $x^{\mathrm{pub}}=\frac{1}{2}$, the optimal $x^{\mathrm{pub}}$ for $x^{\mathrm{pvt}}=0$, and find out which option is the optimal behavior for the incumbent.

As in the proof of Claim (1), in the region in which $\theta_{\beta}$ is constant (either the constant 1 or 0 ), the value function is increasing in $x^{\mathrm{pvt}}$ and in $x^{\mathrm{pub}}$. We turn to study the value function in the region in which $\theta_{\beta}$ is not constant. We start by calculating the directional derivatives of the value function $v_{\beta}$ in this region.

$$
\begin{aligned}
& \frac{\partial v}{\partial x^{\mathrm{pub}}}\left(x^{\mathrm{pub}}, x^{\mathrm{pvt}}\right)=\frac{1-\delta+4 \beta \delta+\delta x^{\mathrm{pvt}}\left(\alpha^{\mathrm{pvt}}-\alpha^{\mathrm{pub}}\right)}{\left(1-\delta \theta_{\beta}\left(x^{\mathrm{pub}}, x^{\mathrm{pvt}}\right)\right)^{2}} \\
& \frac{\partial v}{\partial x^{\mathrm{pvt}}}\left(x^{\mathrm{pub}}, x^{\mathrm{pvt}}\right)=\frac{1-\delta+4 \beta \delta-\delta x^{\mathrm{pub}}\left(\alpha^{\mathrm{pvt}}-\alpha^{\mathrm{pub}}\right)}{\left(1-\delta \theta_{\beta}\left(x^{\mathrm{pub}}, x^{\mathrm{pvt}}\right)\right)^{2}}
\end{aligned}
$$

We will now calculate the optimal $x^{\mathrm{pvt}}$ when $x^{\mathrm{pub}}=\frac{1}{2}$. As mentioned above, we restrict attention to the interval $I_{\beta}^{1}$ in which $\theta_{\beta}\left(\frac{1}{2}, x^{\mathrm{pvt}}\right)=1-\frac{\alpha^{\mathrm{pub}}}{2}-\alpha^{\mathrm{pvt}} x^{\mathrm{pvt}}-4 \beta$ that is given by:

- If $-\frac{1}{4} \leq \beta \leq-\frac{\alpha^{\mathrm{pub}}}{8}$, the interval $I_{\beta}^{1}$ is $-\frac{4 \beta+\frac{\alpha^{\mathrm{pub}}}{2}}{\alpha^{\mathrm{pvt}}} \leq x^{\mathrm{pvt}} \leq \frac{1}{2}$.

- If $-\frac{\alpha^{\mathrm{pub}}}{8} \leq \beta \leq 0$, the interval $I_{\beta}^{1}$ is $0 \leq x^{\mathrm{pvt}} \leq \frac{1}{2}$.

- If $0 \leq \beta \leq \frac{\alpha^{\mathrm{pvt}}}{8}$, the interval $I_{\beta}^{1}$ is $0 \leq x^{\mathrm{pvt}} \leq \frac{1-4 \beta-\frac{\alpha^{\mathrm{pub}}}{2}}{\alpha^{\mathrm{pvt}}}$.

- Otherwise the interval $I_{\beta}^{1}$ is empty. 
Substituting $x_{\beta}^{\mathrm{pub}}=\frac{1}{2}$ in Equation (15) we observe that $\frac{\partial v}{\partial x^{\mathrm{pvt}}}\left(\frac{1}{2}, x^{\mathrm{pvt}}\right)>0$ if and only if $\beta>$ $-\frac{1-\delta}{4 \delta}+\frac{\alpha^{\mathrm{pvt}}-\alpha^{\mathrm{pub}}}{8}$. Thus, if

$$
\beta>-\frac{1-\delta}{4 \delta}+\frac{\alpha^{\mathrm{pvt}}-\alpha^{\mathrm{pub}}}{8},
$$

then the directional derivative is positive on $I_{\beta}^{1}$, and it is optimal for the incumbent to steal $x_{\beta}^{\mathrm{pvt}}=\frac{1}{2}$. If, on the other hand,

$$
\beta<-\frac{1-\delta}{4 \delta}+\frac{\alpha^{\mathrm{pvt}}-\alpha^{\mathrm{pub}}}{8},
$$

then the directional derivative is decreasing on $I_{\beta}^{1}$ and it is optimal for the incumbent to steal the lower end of the interval $I_{\beta}^{1}$.

When Equation (16) holds, the shape of the function $x^{\mathrm{pvt}} \mapsto v_{\beta}\left(\frac{1}{2}, x^{\mathrm{pvt}}\right)$ is see-saw: it increases until the lower end of $I_{\beta}^{1}$, decreases up to the upper end of $I_{\beta}^{1}$, and then increases up to $\frac{1}{2}$ (in case $\frac{1}{2}$ is not the upper end of $\left.I_{\beta}^{1}\right)$. It follows that the optimal $x^{\mathrm{pvt}}$ is either the lower end of the interval $I_{\beta}^{1}$ or $\frac{1}{2}$. When $\beta \leq 0$, the upper end of $I_{\beta}^{1}$ is $\frac{1}{2}$, hence the optimal $x^{\mathrm{pvt}}$ is attained at the lower end of $I_{\beta}^{1}$. When $\beta>0$, to calculate the optimal $x^{\text {pvt }}$ we need to compare $v_{\beta}\left(\frac{1}{2}, \frac{1}{2}\right)=1$ and $v_{\beta}\left(\frac{1}{2}, 0\right)=\frac{1}{2(1-\delta)}$. Simple calculations show that if $\delta<\frac{1}{2}$ then $v_{\beta}\left(\frac{1}{2}, \frac{1}{2}\right)>v_{\beta}\left(\frac{1}{2}, 0\right)$ and $x^{\text {pvt }}=\frac{1}{2}$ is optimal, while if $\delta>\frac{1}{2}$ then $v_{\beta}\left(\frac{1}{2}, \frac{1}{2}\right)<v_{\beta}\left(\frac{1}{2}, 0\right)$ and $x^{\text {pvt }}=0$ is optimal. We note that the last case we considered is possible only when $0 \leq \beta<-\frac{1-\delta}{4 \delta}+\frac{\alpha^{\mathrm{pvt}}-\alpha^{\mathrm{pub}}}{8}$, which implies that $\delta>\frac{2}{2+\alpha^{\mathrm{pvt}}-\alpha^{\mathrm{pub}}} \geq \frac{1}{2}$, and therefore in this case the optimal amount of private good to steal is $x^{\mathrm{pvt}}=0$. We finally note that the quantity $-\frac{1-\delta}{4 \delta}+\frac{\alpha^{\mathrm{pvt}}-\alpha^{\mathrm{pub}}}{8}$ can take any value in $\left(-\infty, \frac{1}{4}\right)$. To summarize, the optimal behavior when $x^{\text {pub }}=\frac{1}{2}$ is given by the following table:

\begin{tabular}{ll} 
range of $\beta$ & $x^{\mathrm{pvt}}$ \\
\hline$\beta \leq-\frac{1}{4}$ & $\frac{1}{2}$, \\
$-\frac{1}{4} \leq \beta \leq-\frac{\alpha^{\mathrm{pub}}}{8}$ & $-\frac{4 \beta+\frac{\alpha^{\mathrm{pub}}}{2}}{\alpha^{\mathrm{pvt}}}$, \\
$-\frac{\alpha^{\mathrm{pub}}}{8} \leq 0$ & 0, \\
$0 \leq \beta \leq-\frac{1-\delta}{4 \delta}+\frac{\alpha^{\mathrm{pvt}}-\alpha^{\mathrm{pub}}}{8}$ & 0, \\
$-\frac{1-\delta}{4 \delta}+\frac{\alpha^{\mathrm{pvt}}-\alpha^{\mathrm{pub}}}{8} \leq \beta$ & $\frac{1}{2}$.
\end{tabular}

We note that the second and third lines in this table may be missing; this happens when $-\frac{1-\delta}{4 \delta}+$ $\frac{\alpha^{\mathrm{pvt}}-\alpha^{\mathrm{pub}}}{8}<0$.

We now calculate the optimal $x^{\text {pub }}$ when $x^{\text {pvt }}=0$. The analysis is analogous to the previous case. We concentrate on the interval $I_{\beta}^{2}$ in which $\theta_{\beta}\left(x^{\mathrm{pub}}, 0\right)=1-\alpha^{\mathrm{pub}} x^{\mathrm{pub}}-4 \beta$. This interval is given by:

- If $-\frac{\alpha^{\mathrm{pub}}}{8} \leq \beta \leq 0$, the interval $I_{\beta}^{2}$ is $-\frac{4 \beta}{\alpha^{\mathrm{pub}}} \leq x^{\mathrm{pub}} \leq \frac{1}{2}$.

- If $0 \leq \beta \leq \frac{\alpha^{\mathrm{pvt}}}{8}$, the interval $I_{\beta}^{2}$ is $0 \leq x^{\mathrm{pub}} \leq \frac{1}{2}$.

- If $\frac{\alpha^{\mathrm{pvt}}}{8} \leq \beta \leq \frac{1}{4}$, the interval $I_{\beta}^{2}$ is $0 \leq x^{\mathrm{pub}} \leq \frac{1-4 \beta}{\alpha^{\mathrm{pub}}}$.

- Otherwise the interval $I_{\beta}^{2}$ is empty. 
On the interval $I_{\beta}^{2}$, the directional derivative $\frac{\partial v}{\partial x^{\mathrm{pub}}}$ is given by $\frac{\partial v}{\partial x^{\mathrm{pub}}}\left(x^{\mathrm{pub}}, x^{\mathrm{pvt}}\right)=\frac{1-\delta+4 \beta \delta}{\left(\left(1-\delta \theta_{\beta}\left(x^{\mathrm{pub}}, x^{\mathrm{pvt}}\right)\right)^{2}\right.}$. If $\beta>-\frac{1-\delta}{4 \delta}$ then the derivative $\frac{\partial v_{\beta}}{\partial x^{\mathrm{pub}}}\left(x^{\mathrm{pub}}, 0\right)$ is positive on $I_{\beta}^{2}$, hence the optimal amount of public good to steal is $x^{\text {pub }}=\frac{1}{2}$.

If, on the other hand, $\beta<-\frac{1-\delta}{4 \delta}$ then the derivative $\frac{\partial v_{\beta}}{\partial x^{\mathrm{pub}}}\left(x^{\mathrm{pub}}, 0\right)$ is negative whenever $\theta_{\beta}\left(x^{\mathrm{pub}}, 0\right)=1-\alpha^{\mathrm{pub}} x^{\mathrm{pub}}-4 \beta$. Since $\beta$ is negative, either $\beta \leq-\frac{\alpha^{\mathrm{pub}}}{8}$, in which case the interval $I_{\beta}^{2}$ is empty, and the optimal amount of public good to steal is $x^{\mathrm{pub}}=\frac{1}{2}$, or $-\frac{\alpha^{\mathrm{pub}}}{8}<\beta<-\frac{1-\delta}{4 \delta}$, in which case the optimal amount of public good to steal is the lower end of the interval $I_{\beta}^{2}$, namely $x^{\mathrm{pub}}=-\frac{4 \beta}{\alpha^{\mathrm{pub}}}$. To summarize, the optimal behavior when $x^{\mathrm{pvt}}=0$ is given by the following table:

\begin{tabular}{ll} 
range of $\beta$ & $x^{\text {pub }}$ \\
\hline$\beta \leq-\frac{\alpha^{\mathrm{pub}}}{8}$ & $\frac{1}{2}$, \\
$-\frac{\alpha^{\mathrm{pub}}}{8} \leq \beta \leq-\frac{1-\delta}{4 \delta}$ & $-\frac{4 \beta}{\alpha^{\mathrm{pub}}}$, \\
$-\frac{1-\delta}{4 \delta}$ & $\frac{1}{2}$.
\end{tabular}

Finally we note that the condition $-\frac{1-\delta}{4 \delta}<-\frac{\alpha^{\mathrm{pub}}}{8}$ is equivalent to $\delta<\frac{2}{2+\alpha^{\mathrm{pub}}}$. We now summarize our findings.

1. If $-\frac{1-\delta}{4 \delta}<-\frac{\alpha^{\mathrm{pub}}}{8}$, when $x^{\mathrm{pvt}}=0$ the optimal solution is $x_{\beta}^{\mathrm{pub}}=\frac{1}{2}$. Indeed, for $\beta<-\frac{\alpha^{\mathrm{pub}}}{8}$ the interval $I_{\beta}^{2}$ is empty, while for $\beta \geq-\frac{1-\delta}{4 \delta}$ the directional derivative is positive on $I_{\beta}^{2}$. It follows that the optimal value of $x^{\text {pvt }}$ is derived from the calculation in the case $x^{\text {pub }}=\frac{1}{2}$. The optimal value of $x^{\mathrm{pvt}}$ depends on the value of $-\frac{1-\delta}{4 \delta}+\frac{\alpha^{\mathrm{pvt}}-\alpha^{\mathrm{pub}}}{8}$. This corresponds to Case (A) of the lemma.

If $-\frac{1-\delta}{4 \delta}+\frac{\alpha^{\mathrm{pvt}}-\alpha^{\mathrm{pub}}}{8} \leq-\frac{1}{4}$ then the optimal amount of private good to steal is always $\frac{1}{2}$. This inequality solves to $\delta<\frac{2}{4+\alpha^{\mathrm{pvt}}-\alpha^{\mathrm{pub}}}$, and corresponds to Case (A.1).

If $-\frac{1}{4} \leq-\frac{1-\delta}{4 \delta}+\frac{\alpha^{\mathrm{pvt}}-\alpha^{\mathrm{pub}}}{8} \leq-\frac{\alpha^{\mathrm{pub}}}{8}$ then for $\beta \in\left(-\frac{1}{4},-\frac{1-\delta}{4 \delta}+\frac{\alpha^{\mathrm{pvt}}-\alpha^{\mathrm{pub}}}{8}\right)$ the optimal amount of private good to steal is $-\frac{4 \beta+\frac{\alpha^{\mathrm{pub}}}{2}}{\alpha^{\mathrm{pvt}}}$. This inequality solves to $\frac{2}{4+\alpha^{\mathrm{pvt}}-\alpha^{\mathrm{pub}}} \leq \delta \leq \frac{2}{2+\alpha^{\mathrm{pvt}}}$, and corresponds to Case (A.2).

If $-\frac{\alpha^{\mathrm{pub}}}{8} \leq-\frac{1-\delta}{4 \delta}+\frac{\alpha^{\mathrm{pvt}}-\alpha^{\mathrm{pub}}}{8}$ then for $\beta \in\left(-\frac{\alpha^{\mathrm{pub}}}{8},-\frac{1-\delta}{4 \delta}+\frac{\alpha^{\mathrm{pvt}}-\alpha^{\mathrm{pub}}}{8}\right)$ the optimal amount of private good to steal is 0 . This inequality solves to $\frac{2}{2+\alpha^{\mathrm{pvt}}} \leq \delta$, and corresponds to Case(A.3).

2. If $-\frac{\alpha^{\mathrm{pub}}}{8}<-\frac{1-\delta}{4 \delta}$ then

(a) When $x^{\mathrm{pvt}}=0$, the optimal amount of public good to steal is $x^{\mathrm{pub}}=\frac{1}{2}$, unless $-\frac{\alpha^{\mathrm{pub}}}{8} \leq$ $\beta \leq-\frac{1-\delta}{4 \delta}$. This implies that when $\beta \leq-\frac{\alpha^{\mathrm{pub}}}{8}$ or $-\frac{1-\delta}{4 \delta} \leq \beta$ we have $x_{\beta}^{\mathrm{pub}}=\frac{1}{2}$, which corresponds to all rows except the third row in the table in Case (B).

(b) For the third row in Case (B) we note that the optimal amount of private good to steal when $x^{\mathrm{pub}}=\frac{1}{2}$ is $x^{\mathrm{pvt}}=0$. Hence the optimal amount of private good to steal is $x_{\beta}^{\mathrm{pvt}}$, and the optimal amount of public good to steal was calculated for this case above.

\section{Proof of Claim (2).}


Recall that we assumed $\alpha^{\text {pvt }}>1>\alpha^{\text {pub }}$.

Part (A) implies that the function $x_{\beta}^{\mathrm{pub}}$ is constant in both regions whenever $\delta \leq \frac{2}{2+\alpha^{\mathrm{pub}}}$, and Part (B) implies that it has a U-shape in the negative region and is constant in the positive region whenever $\delta \geq \frac{2}{2+\alpha^{\mathrm{pub}}}$. We turn to study the shape of the function $x^{\mathrm{pvt}}$.

Part (A.1) shows that the function $x_{\beta}^{\mathrm{pvt}}$ is constant in both regions whenever $\delta \leq \frac{2}{4+\alpha^{\mathrm{pvt}}-\alpha^{\mathrm{pub}}}$, which explains the first row in the table in Claim 2.

Denote $\delta_{*}:=\frac{2}{2+\alpha^{\mathrm{pvt}}-\alpha^{\mathrm{pub}}}$, which is smaller than 1 because $\alpha^{\mathrm{pvt}}>\alpha^{\mathrm{pub}}$. This discount factor satisfies $-\frac{1-\delta_{*}}{4 \delta_{*}}+\frac{\alpha^{\mathrm{pvt}}-\alpha^{\mathrm{pub}}}{8}=0$, so that one of the cutoff points in Parts (A.2), (A.3), and (B) is 0 . In particular, $\delta<\delta_{*}$ if and only if $-\frac{1-\delta}{4 \delta}+\frac{\alpha^{\mathrm{pvt}}-\alpha^{\mathrm{pub}}}{8}<0$.

Since $\frac{2}{2+\alpha^{\mathrm{pvt}}}<\frac{2}{2+\alpha^{\mathrm{pvt}}-\alpha^{\mathrm{pub}}}$, in Part (A.2) the function $x_{\beta}^{\text {pvt }}$ has a U-shape in the negative region and is constant in the positive region.

If $\frac{2}{2+\alpha^{\text {pub }}} \leq \delta_{*}$ (which holds when $\alpha^{\text {pvt }} \leq \frac{4}{3}$ ), then in Part (A.3) the function $x_{\beta}^{\text {pvt }}$ has a U-shape in the negative region and is constant in the positive region. If, on the other hand, $\delta_{*} \leq \frac{2}{2+\alpha^{\mathrm{pub}}}$, then in Part (A.3) the function $x_{\beta}^{\mathrm{pvt}}$ is monotonic nonincreasing in both regions.

In Part $(\mathrm{B})$ the function $x_{\beta}^{\mathrm{pub}}$ has a U-shape in the negative region and is constant in the positive region, and the function $x_{\beta}^{\mathrm{pvt}}$ is monotonic nonincreasing in the negative region. In the positive region, the function $x_{\beta}^{\mathrm{pvt}}$ is constant if $\delta \geq \delta_{*}$ and is monotonic nonincreasing otherwise.

The following list summarizes our findings:

- $\delta_{0}=\frac{2}{4+\alpha^{\mathrm{pvt}}-\alpha^{\mathrm{pub}}}$.

- If $\delta_{*} \leq \frac{2}{2+\alpha^{\mathrm{pub}}}$ then $\delta_{1}=\frac{2}{2+\alpha^{\mathrm{pvt}}}$ and $\delta_{2}=\frac{2}{2+\alpha^{\mathrm{pub}}}$.

- If $\delta_{*} \geq \frac{2}{2+\alpha^{\text {pub }}}$ then $\delta_{1}=\delta_{2}=\frac{2}{2+\alpha^{\text {pub }}}$ (so in particular the third row in the table in Claim 2 is void).

\subsection{Frequency of elections}

An important practical question concerns the relation between the length of the term and the amount that the incumbent steals. In this section we investigate this question. Suppose that election takes place each $n$ periods, for $n \geq 1$. As before, the incumbent maximizes her total expected discounted payoff, while voters vote according to the average level of corruption during the term. The parameter that the incumbent has to determine after each election is the average level of corruption during the current term. Since the problem is stationary, this amount does not depend on calendar time, and is denoted by $x$. Note that since the incumbent maximizes her discounted utility, she will steal more in the first years in office, and will compensate that with a lower level of corruption in later years.

The total expected discounted payoff to the incumbent is

$$
v_{\beta, n}(x)=\frac{x\left(1+\delta+\cdots+\delta^{n-1}\right)}{1-\delta^{n} \theta_{\beta}(x)}=\frac{1-\delta^{n}}{1-\delta} \cdot \frac{x}{1-\delta^{n} \theta_{\beta}(x)} .
$$


The multiplicative term $\frac{1-\delta^{n}}{1-\delta}$ does not affect the strategic decision of the incumbent, hence the optimal average corruption level $x=x_{\beta, n}$ is the same as in the case of $n=1$ that we solved above, with the only exception that the discount factor is $\delta^{n}$ rather than $\delta$.

In both models of Sections (2.1) and (2.3), the discount factor affected the optimal behavior only through the cutoffs $-\frac{1-\delta}{4 \delta}$ and $-\frac{1-\delta}{4 \delta}+\frac{\alpha^{\mathrm{pvt}}-\alpha^{\mathrm{pub}}}{8}$. Both of these cutoffs increase as the incumbent becomes more patient. When $n$ decreases, $\delta^{n}$ increases, and therefore when terms are shortened the cutoffs increase. As can be seen in Figures 2 and 3, it follows that when the discount factor increases, the range in which the incumbent does not steal the whole pot increases. We deduce that in our model, shortening the term in office (increasing the frequency of elections) increases the range in which corruption is low. 